\title{
Thermal Stability of Nanostructured Coatings
}

\author{
A. Fabrizi ${ }^{1, a}$, M. Cabibbo ${ }^{* 1, b}$, R. Cecchini ${ }^{1, c}$, S. Spigarelli ${ }^{1, d}$, C. Paternoster ${ }^{2, e}$, \\ M. Haidopoulo ${ }^{3, f}$ and Ph.V. Kiryukhantsev-Korneev ${ }^{4}$
}

${ }^{1}$ Department of Mechanical Engineering, Marche Polytechnic University, Via Brecce Bianche, 60131-Ancona, Italy

${ }^{2}$ Chemicals and Materials Department, Université Libre de Bruxelles, Av. F.D. Roosevelt 50, 1050 Brussels, Belgium

${ }^{3}$ VINF/Arcelor Mittal, Research Liege, Bld. De Colonster B57, B4000-Liege, Belgium

${ }^{4}$ VINF/ Scientific-Educational Center of SHS, Moscow State Institute of Steel and Alloys, Leninsky pr. 4, Moscow 119049, Russia

a a.fabrizi@univpm.it; ${ }^{b}$ m.cabibbo@univpm.it; ${ }^{c}$ r.cecchini@univpm.it

d s.spigarelli@univpm.it; ${ }^{e}$ carlopaternoster@tiscali.it; ${ }^{\dagger}$ marie.haidopoulo@arcelormittal.com

*: M.Cabibbo (Marcello Cabibbo) corresponding author.

Keywords: Hard coatings; CrN-based coatings; BN-based coatings; thermal treatments; nanoindentation; GIXRD; TEM

\begin{abstract}
This paper is a review of the thermal stability of nanostructured nitride coatings synthesised by reactive magnetron sputtering technique. In the last three decade, nitride based coatings have been widely applied as hard wear-protective coatings in mechanical components. More recently, a larger interest has been addressed to evaluate the thermal stability of such coatings, as their mechanical and tribological properties are deteriorated at high working temperatures.

This study describes the microstructural, mechanical and compositional stability of nanocrystalline $\mathrm{Cr}-\mathrm{N}$ and nano-composited Ti-N based coatings (Ti-Al-Si-B-N and Ti-Cr-B-N) after air and vacuum annealing. For $\mathrm{Cr}-\mathrm{N}$ coatings annealing in vacuum induces phase transformation from $\mathrm{CrN}$ to $\mathrm{Cr}_{2} \mathrm{~N}$, while after annealing in air only $\mathrm{Cr}_{2} \mathrm{O}_{3}$ phase is present. For Ti-N based coatings, a well-definite multilayered structure was shown after air annealing. Degradation of mechanical properties was observed for all the nitride coatings after thermal annealing in air.
\end{abstract}

\section{Introduction}

Corrosion resistance is usually one of the major requirements in the selection of a particular grade of stainless steel for a given application. Chemical composition, surface treatment, heat treatment, and fabrication, generally influence the response of a given stainless steel grade in a specific environment. Among all the stainless steels [1], AISI 304 grade is one of the most commonly used. It has good corrosion resistance in most environments and also in saturated oxidizing acid solutions. Nevertheless, it has not satisfactory corrosion resistance in chloride or non-oxidizing acid solutions, which constitutes the major drawback of this stainless steel grade [2]. One effective means to overcome this disadvantage is the surface coating by physical vapour deposition (PVD) $[3,4]$. It is known that mostly nitrides or carbides, produced by PVD, are able to show a rather good corrosion resistance of the austenitic stainless steels in different reactive environments $[3,4]$. PVD generally refers to three generic coating methods that involve evaporation, ion-implating, and sputtering. The application of one of these three coating processes can be used for depositing virtually any solid film to the surface of any metallic material. This versatility makes PVD especially useful for depositing hard coatings for corrosion and wear-applications [5].

With this respect, the chromium-based nitrides, $\mathrm{Cr}_{2} \mathrm{~N}$ and $\mathrm{CrN}$, deposited by PVD, have been reported to have high hardness, enhanced wear and corrosion resistance, and can be utilized as anti-wear and anti-corrosion coatings [6,7]. The processing conditions during sputtering clearly influence the resulting tribological, mechanical and chemical properties of the films. For example, Pakala and Ray found microhardness rises with increasing nitrogen content in the sputtering gas 
corresponding to the formation of the $\mathrm{Cr}_{2} \mathrm{~N}$ phase [8]. $\mathrm{N}_{2}$ partial pressure plays a very important role in depositing $\mathrm{Cr}-\mathrm{N}$ and its influence on the structure and properties of thin films has been widely studied [9-11].

On the other hand, friction properties are a consequence of structure and orientation of crystals in the film [12]. The corrosion properties also depend on the porosity and density of the coatings [13]. Cr-N coatings have also been used for bending and stamping tools [14,15]. For these reasons, chromium nitrides $(\mathrm{Cr}-\mathrm{N})$ are nowadays considered very popular as coating material for tools and similar products. Tribological behavior at room and elevated temperatures were reported to be quite satisfactory. Yet, only few studies dealt with properties at high temperatures. For instance, Sue et al. compared $\mathrm{TiN}, \mathrm{ZrN}$ and $\mathrm{CrN}$ coatings on steel at temperatures of 770 and $830 \mathrm{~K}$ using a in ring-on-disc test machine. The $\mathrm{CrN}$ coating showed wear rates about one and two orders lower than that of $\mathrm{ZrN}$ and TiN, respectively [16].

Superhardness can be achieved in a variety of ordinary hard coatings either by energetic ion bombardment during their deposition (which results in a variety of effect including a high compressive stress) or by the formation of an appropriate nanostructure, such as superlattices and nanocomposites (see $[17,18]$ and references therein).

$\mathrm{Cr}-\mathrm{N}$ coatings have been reported to have high surface hardness, low coefficient of friction, and high toughness compared with the more conventional TiN [19]. Thus, Cr-N thin films have proven their capability of enhancing the wear protection of a coated piece. In addition to its superior wear resistant property, $\mathrm{Cr}-\mathrm{N}$ is thought to be chemically inert in various environments. Some studies have been performed in acidic solutions $\left(\mathrm{HCl}, \mathrm{H}_{2} \mathrm{SO}_{4}\right)$ or chloride solutions $(\mathrm{NaCl})$ on deposits often made of mixtures of chromium nitrides [20-22].

On the other hand, the hardness rise, due to the energetic ion bombardment, is easy to achieve in a variety of coatings including the so-called 'nanocomposites' $\mathrm{M}(1)_{n} \mathrm{~N}_{\mathrm{y}} \mathrm{M}(2)$. Here $\mathrm{M}(1)$ is a hard and stable transition metal nitride, such as $\mathrm{ZrN}, \mathrm{CrN}$, TiN, etc., and $\mathrm{M}(2)$ is another metal which does not form any thermodynamically stable nitride, such as $\mathrm{Ni}, \mathrm{Cu}$, etc. However, the superhardness is lost when the high stress and other effects induced by the energetic ion bombardment relax upon annealing to $670-870 \mathrm{~K}[17,18]$ or upon a long term storage in air.

The Ti-B-N system represents another class of super-hard coatings which are prepared by a variety of PVD methods, such as vacuum arc evaporation (e.g. [23]) and sputtering [24].

The use of conventional sputtering at a low pressure results either in the formation of a homogeneous phase $\mathrm{TiB}_{2} \mathrm{~N}_{\mathrm{x}}$ [24,25], or a $\mathrm{TiN}_{\mathrm{x}} \mathrm{B}_{\mathrm{y}}$ phase consisting of TiN lattice in which the nitrogen sites are occupied by $33 \%$ of boron, $49 \%$ of nitrogen and $18 \%$ of vacancies, or amorphous $\mathrm{Ti}-\mathrm{B}-\mathrm{N}$ coatings [26]. At a lower boron content, nanocrystalline $\mathrm{TiN}$ and quasi-amorphous $\mathrm{TiB}_{2}$ phase are formed whereas a higher boron content leads to a structure consisting of quasi-amorphous TiN and nanocrystalline $\mathrm{TiB}_{2}$ [27]. The $\mathrm{BN}$ matrix can be hexagonal, amorphous or cubic [28], or even a mixture of f.c.c. TiN, orthorhombic TiB, c-BN and hexagonal Ti-B-N [29]. Hardness of 40$70 \mathrm{GPa}$ was reported in many papers [24-29]. Generally, hardness change with composition does not follow the rule of mixture but displays a maximum at a given composition where the microstructure of the films is very uniform (no columnar growth) and the crystallite size is of few nanometers.

Another very important property of protective films required for industrial application is the thermal stability of their mechanical characteristics at elevated temperatures. For instance, due to the age hardening effect the Ti-B-N films showed the hardness values up to $43 \mathrm{GPa}$ for annealing temperature below $1170 \mathrm{~K}$ [30]. The best $\mathrm{Ti}-\mathrm{Si}-\mathrm{N}$ [31] and $\mathrm{Ti}-\mathrm{Al}-\mathrm{Si}-\mathrm{N}$ [32] nanocomposite films were reported to be stable up to $1370 \mathrm{~K}$.

The oxidation of nitride coatings is an important mechanism leading to the degradation of the mechanical properties and performances at elevated temperatures. The differences in mechanical properties can be attributed to the stress and structure of the $\mathrm{CrN}$ coating at $720-870 \mathrm{~K}$ [33]. $\mathrm{CrN}$ coating would form a dense and stable $\mathrm{Cr}_{2} \mathrm{O}_{3}$ film as a protective scale for thermal oxidation at $1070 \mathrm{~K}$, and a great mechanical integrity with high thermal stability was observed [34]. In many applications, coated tools are exposed to aggressive environments including corrosive 
media, stresses, elevated temperatures or combinations of them. In order to extend the high temperature applications of TiN coatings, ternary $\mathrm{Ti}-\mathrm{Me}-\mathrm{N}$ coating systems (where $\mathrm{Me}$ can be $\mathrm{B}$, $\mathrm{Al}, \mathrm{Si}, \mathrm{Cr}$, and others) have been actively explored and studied [35-37]. Among these, Ti-Al-N coating layer showed, in several studies, improved oxidation resistance compared to that of $\mathrm{TiN}$ coating layers due to the formation of a stable $\mathrm{Al}_{2} \mathrm{O}_{3}$ surface film by migration of aluminium atoms of the coating itself to the surface region [37,38].

On the other hand, $\mathrm{Ti}-\mathrm{Si}-\mathrm{N}$ coatings are generally reported to have nano-composite microstructure with nano-sized TiN crystallites distributed in amorphous $\mathrm{Si}_{3} \mathrm{~N}_{4}$ matrix and to show superhardness above $40 \mathrm{GPa}$ due to its nano-composite microstructure [38]. Ti-Si-N also exhibits significantly improved oxidation resistance compared to that of TiN coating layer. In this ternary system, the amorphous $\mathrm{SiO}_{2}$ formation plays a major role as oxidation barrier [39].

Thus, as a general rule, silicon containing films also showed significantly better oxidation resistance compared to that of TiN. This is due to either the formation of a Si-rich diffusion barrier oxide layer [40] or to the formation of a strong and dense $\mathrm{Si}_{3} \mathrm{~N}_{4}$ interface in nc-TiN/a-Si $\mathrm{N}_{4}$ nanocomposite that hinders oxygen diffusion along the grain boundaries [41]. Recently, Zhang et al. [42] showed that the oxidation of nc-TiN/a- $\mathrm{Si}_{3} \mathrm{~N}_{4}$ takes place by a progressive replacement of nitrogen in both $\mathrm{TiN}$ and $\mathrm{Si}_{3} \mathrm{~N}_{4}$ phases with diffused oxygen. Ti-B-N films are attracting much attention due to the combination of high hardness, wear and corrosion resistance. However, the oxidation resistance of $\mathrm{Ti}-\mathrm{B}-\mathrm{N}$ films was shown to be much lower than that of $\mathrm{Ti}-\mathrm{Si}-\mathrm{N}$ nanocomposite films due to the low oxidation stability of the BN phase [43].

Otani and Hofmann [36] proposed the main rate controlling mechanism of oxidation of TiCrN coating being a combined action of oxygen inward and $\mathrm{Cr}$ outward diffusion. This oxidation mechanism is based upon the fact that oxidation of pure TiN is mainly controlled by the inward diffusion of oxygen through the oxide layer, whereas, for pure $\mathrm{CrN}$, outward diffusion of chromium is the rate determining mechanism. Lee [44] showed that the oxidation phenomena on $\mathrm{TiCrN}$ coatings, deposited on steel substrate, proceeded by not only the inward diffusion of oxygen but also the outward diffusion of $\mathrm{Cr}$ and $\mathrm{Ti}$ to form $\mathrm{Cr}_{2} \mathrm{O}_{3}$ and $\mathrm{TiO}_{2}$, respectively. At the same time, $\mathrm{Fe}$ from the substrate was found to transport outwardly toward the oxide layer. Lee suggested that the TiCrN oxidation is mainly controlled by $\mathrm{Ti}$ and $\mathrm{O}$ diffusion through the dense $\mathrm{Cr}$-oxide layer. In terms of anti-oxidation, silicon seems to be more efficient than $\mathrm{Al}$ and $\mathrm{Cr}$. With films containing $\mathrm{Si}$ [45], a significant oxidation commences at about $1120 \mathrm{~K}$. A comparable result was reached with 26 wt.\% of Al [46]. At $870 \mathrm{~K}$, a minimum oxidation rate was observed with a $32.7 \mathrm{wt} . \%$ of $\mathrm{Cr}$ [36].

Despite a relatively large volume of data pertaining to the high temperature oxidation properties of $\mathrm{Cr}-\mathrm{N}$ coatings, few studies have been performed to assess the thermal stability of the coating microstructure.

This study presents microstructure and mechanical insights in $\mathrm{Cr}-\mathrm{N}$ and Ti-Al-Si-B-N, TiCr-B-N nanostructured coatings on AISI 304. The behavior of 110 to $210 \mathrm{~nm}$ thick $\mathrm{Cr}-\mathrm{N}$ coatings, deposited by reactive magnetron sputtering and then subjected to thermal annealing both in air and vacuum, was investigated. Transmission Electron Microscopy (TEM) and Grazing Incident X-Ray Diffractometry (GIXRD) were used to study crystal structure, Atomic Force Microscopy (AFM) and Scanning Electron Microscopy (SEM) for surface morphology evolution and nanoindentation for hardness measurements. Microstructure and mechanical properties evolution of Ti-Cr-B-N and Ti-Al-Si-B-N, produced by ion implantation assisted magnetron sputtering, were studied by TEM, X-Ray Diffractometry (XRD) and nanoindentation. Oxidation phenomena and thermal stability of the Ti-Al-Si-B-N and Ti-Cr-B-N were investigated. Air annealing aimed at studying the performance of the coating in an oxidizing environment, while vacuum annealing experiments allowed to determine the mechanisms of diffusion and grain growth of the thin-film constituting phases. 


\section{Experimental details and methods}

\subsection{The materials and deposition methods.}

Three different $\mathrm{Cr}-\mathrm{N}$ nanostructured coatings were deposited on AISI 304 stainless steel substrate (in the following referred to as sample A, B, C). Ti-Cr-B-N and Ti-Al-Si-B-N coatings were deposited on single crystal $\mathrm{Si}_{100}$ and AISI 304 with a commercial 2B surface finish consisting of a pickling process after several stages of hot and cold rolling, and of a final skin pass. Ti-Cr-B-N and Ti-Al-Si-B-N coatings were also deposited on single crystal $\mathrm{Si}(100)$ by ion implantation assisted magnetron sputtering (IIAMS) in which magnetron sputtering is combined with a Ti ions source. The Cr-N coatings were deposited by Cockerill Sambre ARCELOR-MITTAL (Belgium) while the Ti-N based coatings were produced by Moscow State Institute of Steel and Alloy (MSISA) in Russia.

Flat AISI 304 sheets of $1.5 \mathrm{~m}$ with and thickness of $0.6 \mathrm{~mm}$ were pre-treated by Ar-plasma etching and coated using Direct Current (DC) reactive sputtering in a $\mathrm{Ar} / \mathrm{N}_{2}$ mixture atmosphere. Plasma composition was monitored by Optical Emission Spectroscopy (OES) during deposition. Deposition conditions were defined by the $\mathrm{Cr} / \mathrm{Ar}$ ionic ratios in the plasma and $\mathrm{N}_{2}$ flow. $\mathrm{Cr} / \mathrm{Ar}$ ratios were: $0.65,0.65$ and 0.85 for type $\mathrm{A}, \mathrm{B}$ and $\mathrm{C}$ respectively. Three different $\mathrm{N}_{2}$ flow regimes were used: high for type A, medium for type B and low for type C.

From each type of the $\mathrm{Cr}-\mathrm{N}$ coated sheets, several samples of $1 \times 2 \mathrm{~cm}^{2}$ were extracted using a water cooled diamond blade. Coatings thicknesses, measured by AFM, were $(210 \pm 20) \mathrm{nm},(140$ $\pm 10) \mathrm{nm}$ and $(110 \pm 10) \mathrm{nm}$ for samples $\mathrm{A}, \mathrm{B}$ and $\mathrm{C}$ respectively.

For the for Ti-Cr-B-N and Ti-Al-Si-B-N coatings, the deposition process was performed by IIAMS apparatus [47] in a gaseous mixture of $\mathrm{Ar}+\mathrm{N}_{2}$. Prior to deposition, the surface of substrates was ion etched by Ar beam with energy of $1.5 \mathrm{KeV}$ for 10 minutes in order to remove oxides and impurity atoms on the surface. The total pressure in the chamber was maintained at $0.01 \mathrm{~Pa}$ and the partial pressure of $\mathrm{N}_{2}$ was of $15 \%$ of the total one. TiCrB and TiAlSiB composite targets were synthesized by combined force self-propagating high-temperature synthesis-pressing technology (SHS). Targets compositions are described in [48].

The diameter of the targets was $125 \mathrm{~mm}$ and the target to substrate distance was $100 \mathrm{~mm}$. Discharge magnetic current during sputtering was $2.3 \mathrm{~A}$ and a bias voltage of $-250 \mathrm{~V}$ was applied to the substrate. Ti ion implantation source was used at $20 \mathrm{kV}$ of accelerating voltage and an ions flux of $1.5 \cdot 10^{14}$ ions $/\left(\mathrm{cm}^{2} \mathrm{~s}\right)$. Energy dispersive spectrometry (EDS) measurement of the Ti-Cr-B-N coating gave a $\mathrm{Ti} / \mathrm{Cr}=2.6$, while, for $\mathrm{Ti}-\mathrm{Al}-\mathrm{Si}-\mathrm{B}-\mathrm{N}$ was $\mathrm{Ti} / \mathrm{Al}=2.8$ and $\mathrm{Ti} / \mathrm{Si}=2.9$. Coatings and samples characteristics are summarized in Table 1.

Table 1. Cr-N and Ti-Al-Si-B-N, Ti-Cr-B-N coating characteristics.

\begin{tabular}{|c|c|c|c|c|c|c|c|c|c|}
\hline \multirow{2}{*}{ Coating } & \multirow{2}{*}{ Substrate } & \multicolumn{8}{|c|}{ Deposition Parameters } \\
\hline & & $\begin{array}{c}C r / A \\
r\end{array}$ & $\mathrm{Ti} / \mathrm{Cr}$ & $T i / A l$ & $\mathrm{Ti} / \mathrm{Si}$ & $\begin{array}{c}\text { Thicknes } \\
\text { s [nm] }\end{array}$ & $\begin{array}{c}\text { Total Pressure } \\
{[\mathrm{Pa}]}\end{array}$ & $N_{2} /\left(N_{2}+A r\right)$ & $\begin{array}{c}\text { Discharge current } \\
{[A]}\end{array}$ \\
\hline $\mathrm{Cr}-\mathrm{N}$ (A) & AISI 304 & 0.65 & - & - & - & $210 \pm 20$ & - & - & - \\
\hline $\mathrm{Cr}-\mathrm{N}(\mathrm{B})$ & AISI 304 & 0.65 & - & - & - & $140 \pm 10$ & - & - & - \\
\hline $\mathrm{Cr}-\mathrm{N}(\mathrm{C})$ & AISI 304 & 0.85 & - & - & - & $110 \pm 10$ & - & - & - \\
\hline Ti-Al-Si-B-N & AISI $304, \mathrm{Si}$ & - & - & 2.8 & 2.9 & $\sim 2000$ & 0.1 & $14 \%$ & 2.3 \\
\hline Ti-Cr-B-N & AISI 304, Si & - & 2.6 & - & - & $\sim 2000$ & 0.1 & $14 \%$ & 2.3 \\
\hline
\end{tabular}

\subsection{Microstructure inspections.}

Morphological inspections were performed using a PHILIPS® XL20 SEM equipped with a EDS ( Energie Dispervise Spectroscopy) system and a BURLEIGH INSTRUMENTS® Metris2001 AFM in contact mode. TEM discs from Cr-N/steel and Ti-X-B-N/Si samples were prepared respectivily in-plane view and in cross-section configuration. The TEM discs were mechanically polished to $100 \mu \mathrm{m}$, thinned to $\sim 20 \mu \mathrm{m}$ by dimpling and then ion milled to electron transparency. 
XRD measurements were performed both in the $\theta-2 \theta$ geometry (SIEMENS $®$ D5000, Cu waveleght $\lambda=0.154 \mathrm{~nm}, 30 \mathrm{kV}, 40 \mathrm{~mA}$ ) and GIXRD (INEL ${ }^{\circledR}$ CPS120, Cu waveleght $\lambda=0.154 \mathrm{~nm}, 30 \mathrm{kV}$, $40 \mathrm{~mA})$.

\subsection{Thermal treatments.}

For the Cr-N coatings, thermal annealing was performed at $920 \mathrm{~K}$ both in air and vacuum (2.0.10-4 Pa) for $1,2,4$ and $8 \mathrm{~h}$. After annealing, samples were left to cool in air and vacuum respectively at room temperature.

All thermal annealing treatments of $\mathrm{Ti}-\mathrm{Cr}-\mathrm{B}-\mathrm{N}$ and $\mathrm{Ti}-\mathrm{Al}-\mathrm{Si}-\mathrm{B}-\mathrm{N}$ coatings were performed in air at $1170 \mathrm{~K} / 4 \mathrm{~h}$. After annealing, samples were left to cool in air at room temperature. Phases and microstructure were investigated by a X-ray diffractometer and a PHILIPS ${ }^{\circledR}$ CM 200 TEM operating at $200 \mathrm{kV}$, equipped with an EDS.

Thermal cycling was performed in air by repeatedly moving the Cr-N/steel samples in and out of a furnace for a set number of cycles. During thermal cycling, the heating and cooling curves depended on the furnace temperature ( $\left.T_{\text {setup furnace }}\right)$ and on the time of permanence inside and outside the furnace. The furnace and sample temperatures were measured by two thermocouples, one connected to the furnace and the other to the sample. Number of cycles, time of permanence of the sample inside and outside the furnace and $T_{\text {setup furnace }}$ were controlled by a dedicated software. During each cycle, the samples were kept for $150 \mathrm{sec}$ inside the furnace, rapidly moved outside the furnace, kept in this position for $150 \mathrm{sec}$, then rapidly moved back inside the furnace. Four different thermal cycling treatments were performed, at increasing $T_{\text {setup furnace: }} 725,925,1045$ and $1175 \mathrm{~K}$. The recorded $T_{\min }$ and $T_{\max }$ were respectively 425 and $585 \mathrm{~K}, 510$ and $755 \mathrm{~K}, 530$ and $910 \mathrm{~K}, 605$ and $1075 \mathrm{~K}$. The temperature rise and fall rate were 1.0, 1.5, 2.5 and $3.0 \mathrm{~K} / \mathrm{sec}$ respectively. The number of cycles was fixed to 120 for all the tests, corresponding to a 6 hour-duration per test.

\subsection{Mechanical properties.}

Indentation measurements were performed using a Hysitron ${ }^{\odot}$ UBI $^{\circledR}$ I Nanoindenter, equipped with a motorized stage. To estimate the Young's modulus unload curves. A Berkovich diamond tip was used. Tip was calibrated with a fused quartz reference sample. Analyses were done according to the Oliver and Pharr method [49]. For the morphological analyses, the nanoindenter was operated in scanning probe mode (SPM). Identification of the different layers in the cross section samples was thus possible. Mechanical properties were inferred on the coating surfaces with indentation sequence of loading and unloading time of $5 \mathrm{sec}$, holding at the maximum load being of 4sec. The applied load ranged 500 to $10000 \mu \mathrm{N}$ in a multistep mode. The penetration depth was maintained within $10 \%$ of the film thickness to avoid indentation substrate effects.

Cross section samples were prepared by gluing the samples on a thin silicon plate using twocomponent epoxy resin and then cutting to $500 \mu \mathrm{m}$ tick cross-section slides. The slides were mechanically reduced to a thickness $\sim 100 \mu \mathrm{m}$ and then polished to mirror-like finishing.

\section{Results}

\section{1. $\mathrm{Cr}-\mathrm{N}$ coatings.}

Fig. 1 shows the TEM bright field images of sample $A$ in plane view at different magnifications. At low magnification (Fig. 1(a)), the substrate grain boundaries and the slip bands formed in the rolling stage of the steel are visible. At higher magnification (Fig. 1(b)), the Cr-N crystal structure is visible, showing a very fine structure, with grain sizes ranging 15 to $35 \mathrm{~nm}$. Cr-N grains appeared elongated. Zhao et al. [50] reported similar observations in Cr-N sputtered on Silicon mono-crystal. They explained the grain elongation with the geometrical orientation of the sample substrate with respect to the target during sputtering.

Fig. 2 shows the GIXRD measurements performed on the as-deposited Cr-N/steel samples. The peaks at angles of $43.6^{\circ}, 50.8^{\circ}$ and $74.8^{\circ}$ are due to substrate (111), (200) and (220) planes of austenitic steel, respectively. The $37.4^{\circ}$ peak comes from the $\mathrm{CrN}$ (111) plane. Part of the $43.6^{\circ}$ peak is likely to come from $\mathrm{CrN}$ (200). 

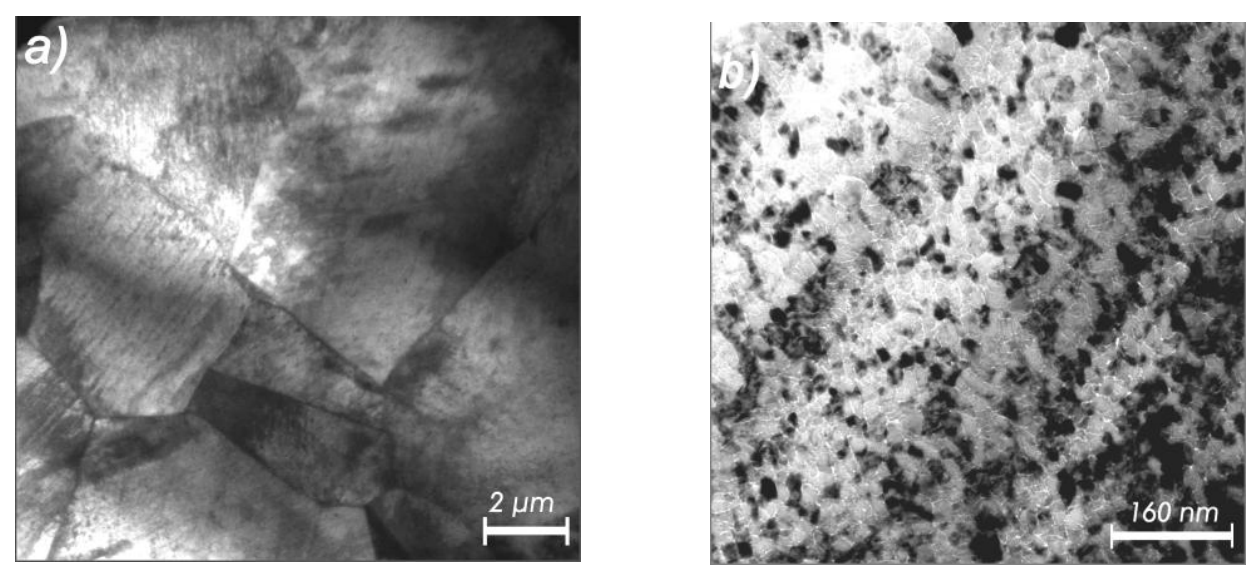

Fig. 1. TEM in plane view of sample A showing: a) substrate grain boundaries and slip bands at low magnification, and b) coating microstructure at higher magnification.

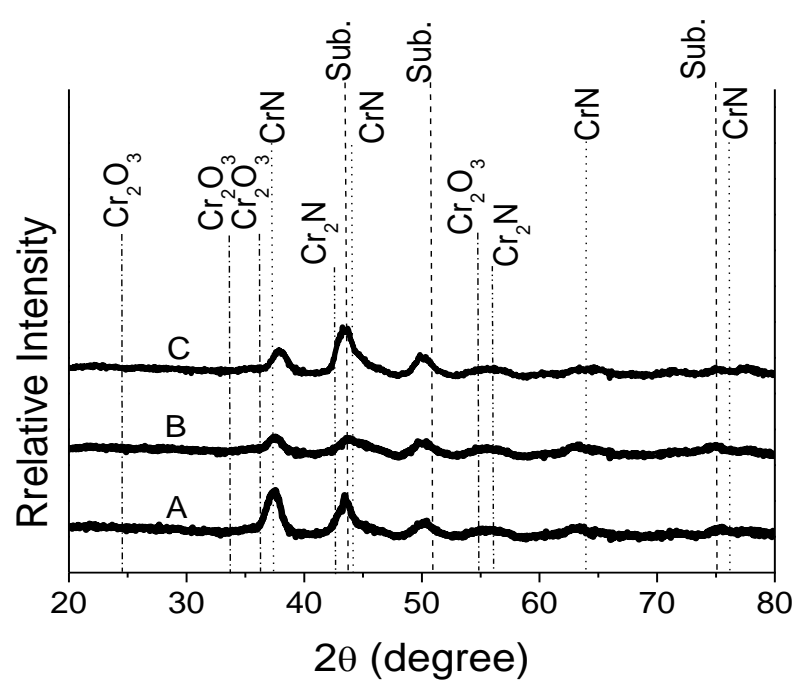

Fig. 2. GIXRD patterns of sample A, sample B and sample $C$ in as-deposited conditions.

Fig. 3(a),(b) reports the GIXRD diffraction patterns for samples A and C, after thermal annealing in vacuum at $920 \mathrm{~K}$ for increasing annealing times. The diffraction pattern of the asdeposited samples is also reported. The intensity of all the peaks recorded on the as-deposited samples shrunk upon annealing. The clear peak at $42.6^{\circ}$, in the annealed conditions, is consistent with diffraction from $\mathrm{Cr}_{2} \mathrm{~N}$ (111) plane. The evolution of samples $\mathrm{A}$ and $\mathrm{C}$ diffraction patterns with respect to $\mathrm{Cr}_{2} \mathrm{~N}$ (111) peak seems to be different. In sample $A$, the intensity of $\mathrm{Cr}_{2} \mathrm{~N}$ (111) peak increases progressively with annealing time. In sample $\mathrm{C}$, the diffraction pattern changes with annealing time are rather modest and not significant.

The diffraction patterns of samples $\mathrm{A}$ and $\mathrm{C}$ after $920 \mathrm{~K}$ air-annealing are reported in Fig. $3(\mathrm{c})$,(d). Peaks corresponding to the $\mathrm{Cr}_{2} \mathrm{O}_{3}$ phase appear on the diffraction patterns starting from $1 \mathrm{~h}$ 
of annealing, with intensity increasing with annealing time. At the same time, CrN phase peaks intensity decreases and have almost completely disappeared after $8 \mathrm{~h}$ of annealing, when only substrate and chromium oxide peaks are present in the diffraction patterns. Samples A and C show a similar diffraction patterns evolution on air-annealing. Sample $\mathrm{C}$ shows $\mathrm{Cr}_{2} \mathrm{O}_{3}$ peaks with higher intensity than sample A. In particular, the $4 \mathrm{~h}$ and $8 \mathrm{~h}$ annealing times, showed a considerable higher intensity at $33.6^{\circ}$ and $54.9^{\circ}$, that correspond to the (104) and (116) $\mathrm{Cr}_{2} \mathrm{O}_{3}$ planes. As for vacuumannealing, sample B shows an intermediate behavior with respect to the diffraction spectrum of samples A and C.
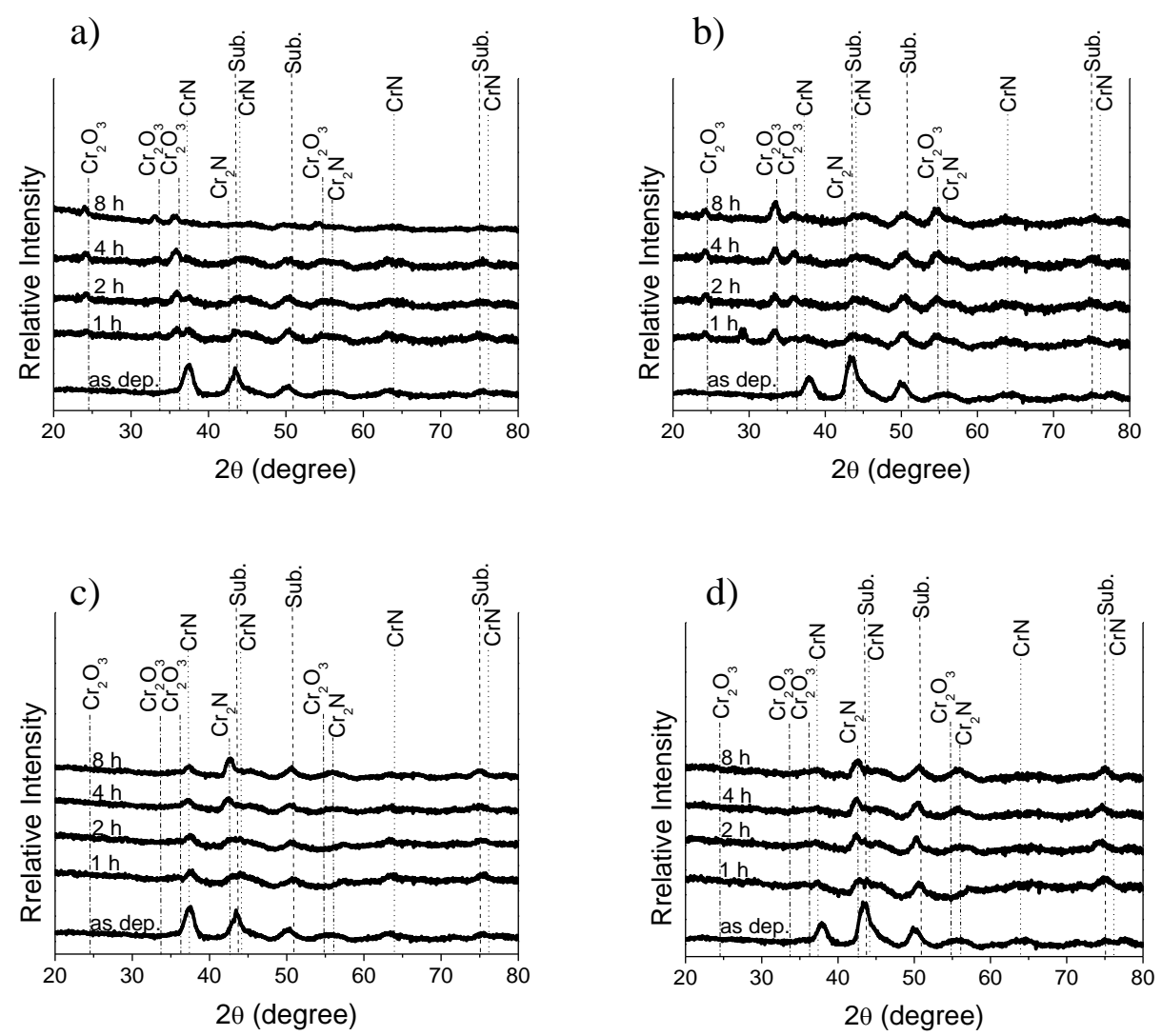

Fig. 3. GIXRD patterns of: a) sample $A$ and b) sample $C$ after annealing at $920 \mathrm{~K}$ in air for 1, 2, 4 and $8 \mathrm{~h}$, and in vacuum for the same durations, c) sample A and d) sample C.

The surface morphologies properties of the as-deposited and annealed samples were studied by AFM. In the as-deposited condition, samples A, B and C show similar Root Mean Square (RMS) surface roughness, whose average value was $\sim 15 \mathrm{~nm}$ [51]. Air annealing, in sample B, led to a significant rise of the surface roughness, already at $1 \mathrm{~h}$ annealing duration. The coating surface morphology changes revealing large host features, identified through GIXRD as $\mathrm{Cr}_{2} \mathrm{O}_{3}$ crystallites, generated by oxidation phenomena.

Fig. 4 shows the GIXRD measurements performed on the $\mathrm{Cr}-\mathrm{N} /$ steel samples before and after thermal cycling. All measurements were taken at a grazing angle of $0.8^{\circ}$. On the as-deposited samples, the three peaks recorded at angles of $38^{\circ}, 43.5^{\circ}$ and $63^{\circ}$ are consistent with the contributions from CrN (111), (200) and (220) planes [52]. The intensity of these peaks decreases with increasing diffraction angle. Peaks due to the austenitic steel (substrate) are also visible on the as-deposited samples. 


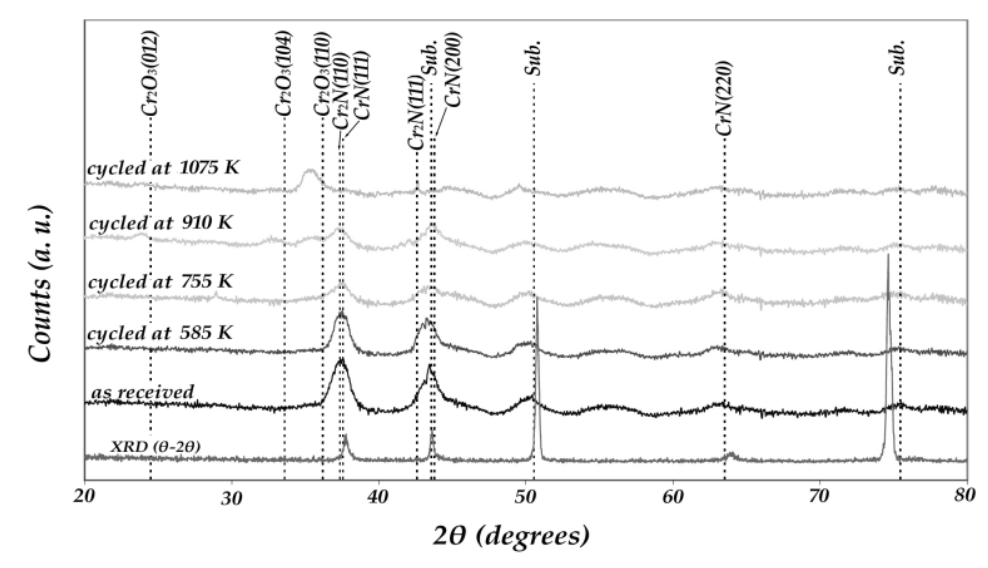

Fig. 4. GIXRD and XRD spectra of the as deposited $\mathrm{Cr}-\mathrm{N} /$ steel samples after different thermal cycling treatments. $\mathrm{CrN}, \mathrm{Cr}_{2} \mathrm{~N}, \mathrm{Cr}_{2} \mathrm{O}_{3}$ and substrate (AISI 304 stainless steel) diffraction angles positions are indicated.

In order to evaluate the morphological evolution induced by thermal cycling, SEM analyses on the Cr-N/steel samples were performed before and after thermal treatments. Fig. 5(a) shows a SEM micrograph taken on the as-deposited sample. Some of the substrate features are still clearly visible: steel grain boundaries and scratches are reproduced on the deposited film. Also the waviness present on the film (Fig. 5(a)) is due to the substrate. This explanation is consistent with the waviness change of orientation from grain to grain in the steel. This is due to the slip bands formed in the rolling stage of the steel. The surface morphology of the coating changes after thermal cycling. The change is more evident at the higher temperatures $T_{\max }$ of the treatment. Fig. 5(b) refers to the sample after thermal cycling $\left(T_{\max }=1075 \mathrm{~K}\right)$, and it shows an increase of the film roughness, which makes the substrate features no longer visible. These morphological modifications are due to $\mathrm{CrN}$ oxidation to $\mathrm{Cr}_{2} \mathrm{O}_{3}$ [53,54], as suggested by the GIXRD analyses. Fig. 5(b) also shows that after cycling the film surface morphology is not longer homogeneous: large crystallites aligned in rows are present on the coating surface. These crystallites have a diameters ranging 0.2 to $1 \mu \mathrm{m}$, and the rows formed are few tens of micrometers long.

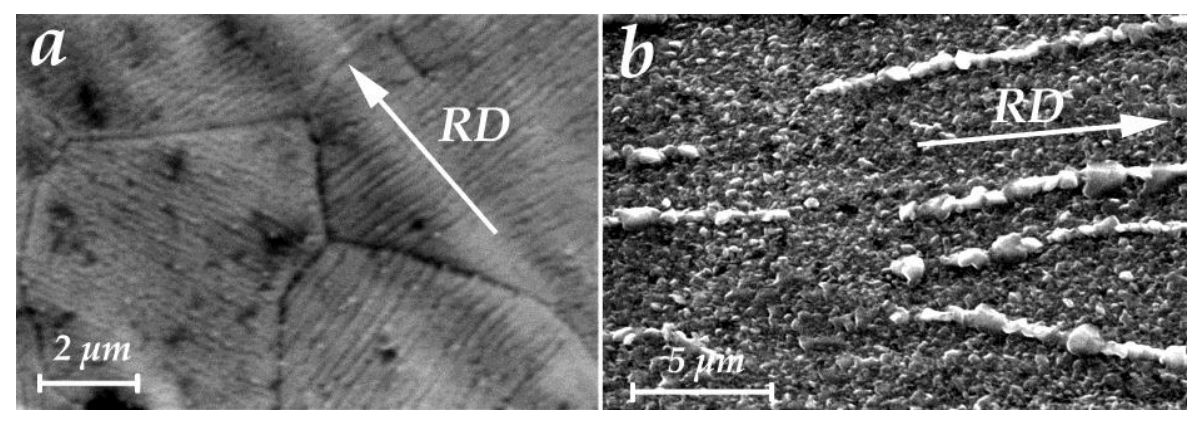

Fig. 5. Representative SEM micrographs of Cr-N/steel samples: a) as-deposited and b) after thermal cycling with $T_{\max }=1075 \mathrm{~K}$. Rolling direction (RD) of steel is indicated.

Sometimes such rows start from a single point and then separate apart. In general, they are oriented along a direction forming an angle of about $30^{\circ}$ with respect to the steel rolling direction. These rows appear at $T_{\max } \geq 755 \mathrm{~K}$ and their surface density increases at higher cycling 
temperatures (910 and $1075 \mathrm{~K}$ ). Surface morphology and roughness evolution of the Cr-N coatings before and after thermal cycling were investigated by AFM. AFM scans were taken in contact mode at different scan sizes. RMS surface roughness was determined from $22.7 \times 22.7 \mu \mathrm{m}^{2}$ scan areas. As it can be seen from Fig. 6(a), the film surface is characterized by parallel grooves, which are due to the slip bands produced on the steel during rolling. Fig. 6(b) shows the film surface after thermal cycling at $T_{\max }=1075 \mathrm{~K}$. The increase of roughness is evident as well as the presence of larger crystallites $(<1 \mu \mathrm{m}$ in diameter $)$.
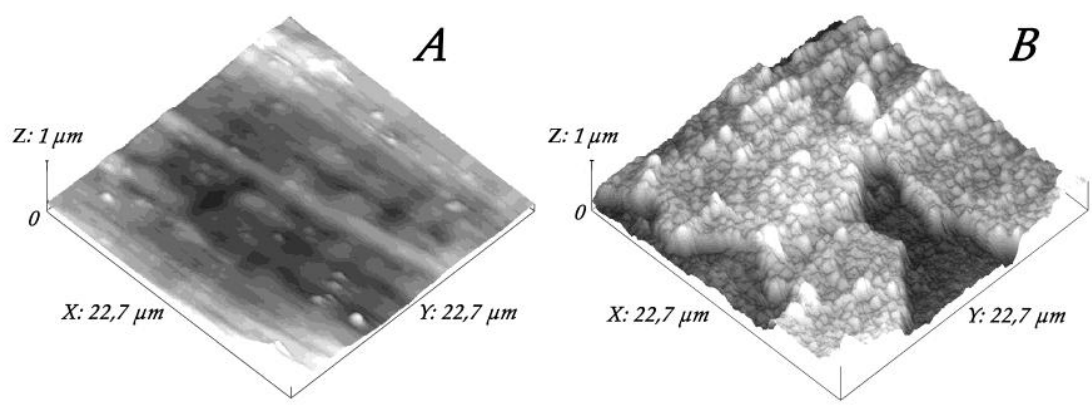

Fig. 6. Representative AFM images of Cr-N coating surface: a) as-deposited and b) after thermal cycling with $T_{\max }=1075 \mathrm{~K}$.

Nanoindentation was used to calculate the hardness of the $\mathrm{Cr}-\mathrm{N}$ coatings, using indentation load-displacement data. Fig. 7 shows the hardness of samples A, B and C in as-deposited condition and after $8 \mathrm{~h}$ of annealing in vacuum as a function of penetration depth. It can be observed that hardness decreases with penetration depth for all the as-deposited and vacuum annealed samples. Hardness of samples $\mathrm{A}, \mathrm{B}$ and $\mathrm{C}$ was measured with penetration depths starting from $15 \mathrm{~nm}$. Largest penetration depths were kept below the film thickness. The hardness behavior as a function of penetration depth is typical of film with higher hardness than the substrate.
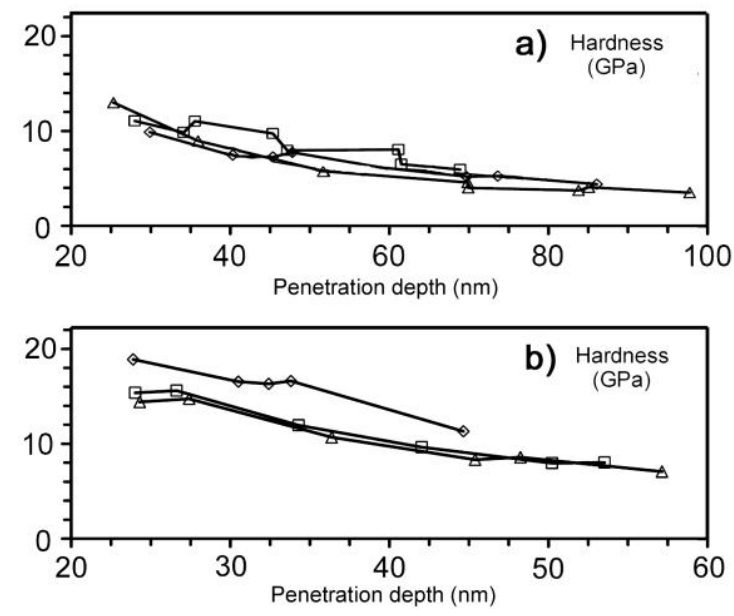

Fig. 7. Nanoindentation measured hardness of: a) as-deposited samples and b) after annealing in vacuum at $920 \mathrm{~K} / 8 \mathrm{~h}$. Sample A $(\longrightarrow$ ), sample B $(\longrightarrow-\square)$, sample C $(\longrightarrow-$ ).

For small penetration depth, the measured hardness approaches the hardness of the film, whereas, for high penetration depths the measured hardness approaches that of the substrate. For all samples the measured hardness tends to $\mathrm{H} \cong 4.5 \mathrm{GPa}$ for large penetration depths. This value is 
consistent with the hardness measured on uncoated regions of substrate, and close to AISI 304 values referred in literature. For the smallest penetration depths of $30 \mathrm{~nm}$, which can be considered not affected by roughness and tip calibration, the hardness of as-deposited $\mathrm{Cr}-\mathrm{N}$ approaches to 10 GPa (Fig. 7(a)). The true hardness of the as-deposited film should then be $>10 \mathrm{GPa}$. A hardness rise of all the samples is found after annealing in vacuum (Fig. 7(b)), with the highest rise on sample A. Due the large increase of roughness after annealing in air, it was not possible to obtain reliable nano-hardness measurements for these sample conditions.

\subsection{Ti-Cr-B-N and Ti-Al-Si-B-N coatings.}

Fig. 8 shows the XRD $\theta-2 \theta$ pattern for as-deposited and thermally annealed Ti-Cr-B-N and Ti-Al-Si-B-N coatings. As-deposited Ti-Cr-B-N/Si samples show broad peaks consistent with the cubic NaCl-type structure of TiN. It can be noticed that the relative intensity of the peak TiN (220) peak is lower than expected for random orientation of the nano-crystals.

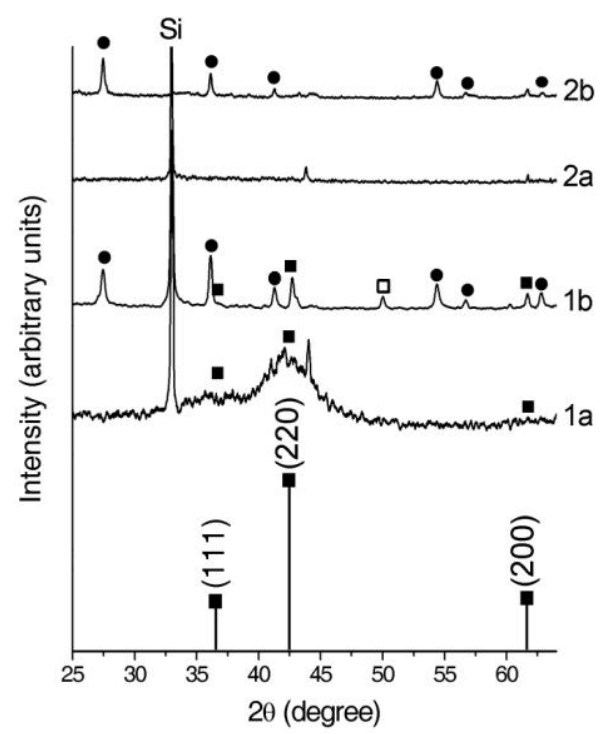

Fig. 8. XRD patterns of as-deposited (1a) and air annealed (1b) Ti-Cr-B-N/Si and as-deposited (2a) and annealed (2b) Ti-Al-Si-B-N/Si samples. TiN (ם), $\mathrm{TiO}_{2}(\bullet)$ and $\mathrm{Cr}_{2} \mathrm{O}_{3}(\square)$ peaks are indicated. On the bottom the relative intensity of stronger peaks from TiN powder diffraction (PDF: 00-038$1420)$ is reported.

The average crystal size in the growth direction was estimated using Scherrer's equation [55]: $D=0.9 \lambda /(B \cos \theta), D$ being the crystal size, $B$ the corrected full-width at half maximum (FWHM) of the Bragg peak, $\lambda$ the X-ray wavelength, and $\theta$ the Bragg angle. $B$ is obtained from the measured XRD patterns after subtracting the instrumental broadening (assuming it is equal to the FWHM of a single-crystal silicon wafer). Using (111) and (200) peaks, the average grain size of TiN crystals in the as-deposited Ti-Cr-B-N/Si samples was found to be 1 to $2 \mathrm{~nm}$.

For Ti-Al-Si-B-N/Si as-deposited samples, only sharp peaks due to impurities in the film appear, indicating the presence a large fraction of amorphous phase compared to the Ti-Cr-B-N coating. Morphology and phase of the as-deposited coatings were further investigated by TEM.

Cross sections of Ti-Cr-B-N/Si samples revealed the presence of columnar structure, as reported in Fig. 9. The relative selected area electron diffraction pattern (SAEDP) shows (111), (200) and (220) TiN rings. The lattice parameter calculated from the diffraction pattern was 0.42 nm. Intensity of the rings confirms (111) and (200) texture of the coatings. It can be noticed that 
(200) ring intensity is not homogeneous, with broad spots that indicate preferential orientation of the crystals parallel to the Si (200) forbidden reflection, i.e. along the growth direction and column length.

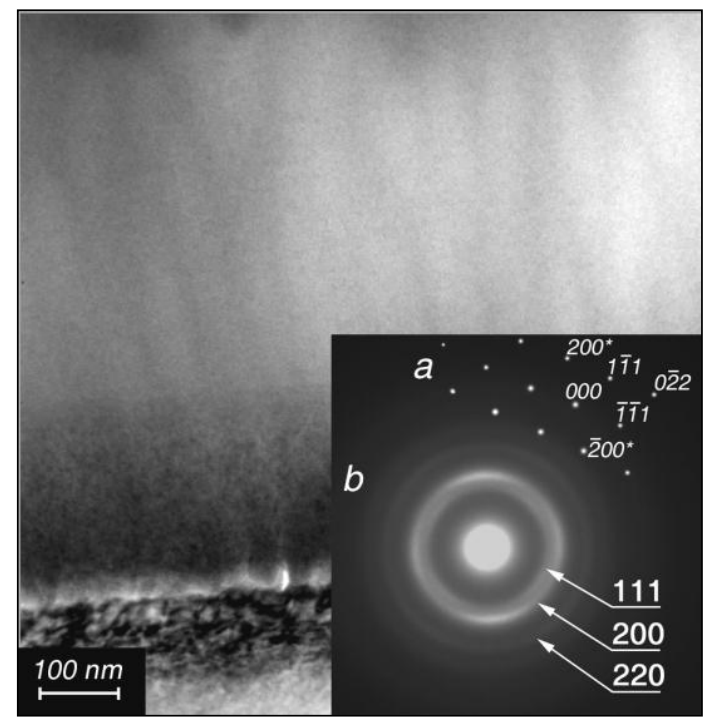

Fig. 9. Cross section TEM bright field image of as-deposited Ti-Cr-B-N/Si. In the insert SAEDP recorded Silicon substrate (a) and from the coating (b) are reported.

After thermal annealing in air at $1170 \mathrm{~K} / 4 \mathrm{~h}, \mathrm{XRD}$ patterns of Ti-Cr-B-N/Si and Ti-Al-Si-B$\mathrm{N} / \mathrm{Si}$ samples (Fig. 8), indicate the presence of rutile- $\mathrm{TiO}_{2}$ and $\mathrm{Cr}_{2} \mathrm{O}_{3}$, and $\mathrm{TiO}_{2}$ phases respectively. TiN phase is also still present on Ti-Cr-B-N/Si samples, and average grain size of TiN crystals increases to $\sim 30 \mathrm{~nm}$.

A more detailed description of annealed coatings on $\mathrm{Si}$ was documented by TEM inspections of the cross section samples. It was seen that oxidation led to increase of average grain size and to formation of a multilayered structure in both coatings (Fig. 10).

The main features of the air annealed Ti-Cr-B-N, Ti-Al-Si-B-N coatings on steel are shown in Fig. 11. Several similarities were revealed in both coatings: the formation of a superficial layer of well-crystallized oxide, the development of layers beneath the top oxidized layer and a diffuse failure of the coatings. The adhesion of Ti-Al-Si-B-N to the steel substrate after the exposition at $1170 \mathrm{~K}$ is generally better than that of Ti-Cr-B-N. However in both the films the adhesion to the substrate is severely compromised after the oxidation process. In Ti-Al-Si-B-N only limited portions of oxidized coating are present.

Generally, the remaining fragments are composed by all the three layers discussed above. The largest amount of coating delamination occurred during the cooling stage of the sample outside the furnace. A residual part of the removed coating, in which Ti is mainly present, fills the valleys between the islands of the substrate and it is thus present on the surface of the coatings. The oxidized top layer, whose topography is quite different from that of the as-deposited sample, shows many regions in which phenomena of buckling are evident.

As the thickness of the coated film $(\sim 2 \mu \mathrm{m})$ is negligible compared with that of AISI 304 substrate $(\sim 600 \mu \mathrm{m})$, the thermal response of the system coating-substrate is mainly controlled by the thermal expansion coefficient of the substrate $\left(\alpha=17.8 \cdot 10^{-6} \mathrm{~m}^{-1}\right)$. The spallation mechanism is evident, in both the coatings (Fig. 11). 
a)
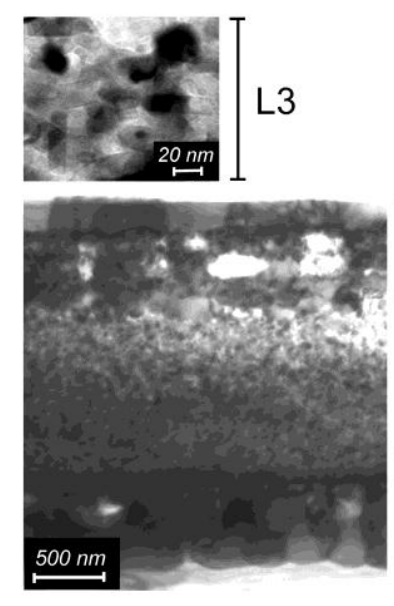

L3

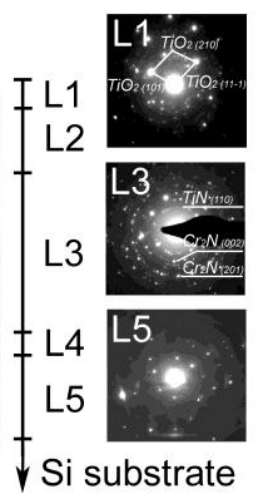

b)
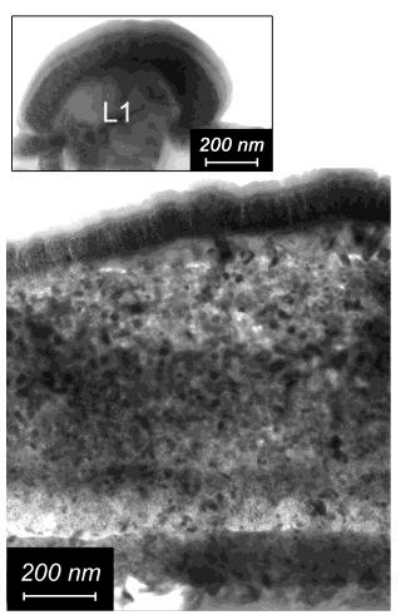

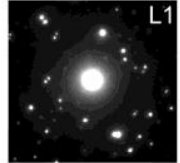

TL2

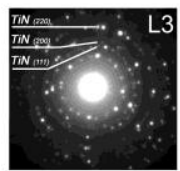

L3

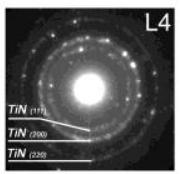

Si substrate

Fig. 10. Cross section TEM bright field image of annealed a) Ti-Cr-B-N/Si, and b) Ti-Al-Si-B-N/Si with indication of the different layers (L). SAEDPs recorded from the different layers (L) are also reported.
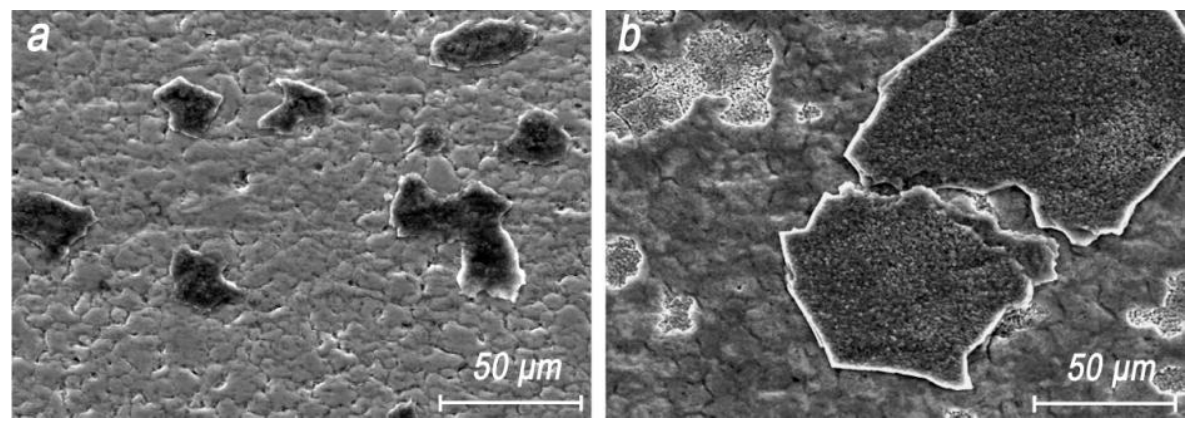

Fig. 11. SEM plan-view of air annealed a) Ti-Al-Si-B-N and b) Ti-Cr-B-N coatings deposited on AISI 304 stainless steel substrate.

EDS analyses were carried out on in-plane and cross-section samples for the determination of the coating layers composition. (Due to the interaction volume of electrons in the EDS analysis, in-plane measurement of each layer includes the contribution of both the layers and of the substrate beneath). It was also possible to analyse the composition of the AISI 304 substrate after the air annealing by direct analyses through the surface craters. The chemical composition of coatings and substrate are reported in Table 2. 
Table 2. Chemical composition (at \%) of Ti-Al-Si-B-N and Ti-Cr-B-N annealed coatings, and AISI 304 substrate.

\begin{tabular}{|c|c|c|c|c|c|c|c|c|}
\hline \multirow{2}{*}{ Sample } & \multirow{2}{*}{ Layer } & \multicolumn{7}{|c|}{ Element composition (at. \%) } \\
\hline & & $T i$ & $A l$ & $\mathrm{Si}$ & $A r$ & $\mathrm{Cr}$ & $\mathrm{Fe}$ & $\mathrm{Ni}$ \\
\hline \multirow{2}{*}{ Ti-Al-Si-B-N } & $\mathrm{L} 1+\mathrm{L} 2$ & 39 & 26 & 5 & 1 & 29 & - & - \\
\hline & L3 & 56 & 12 & 11 & 4 & 17 & - & - \\
\hline \multirow{3}{*}{ Ti-Cr-B-N } & L1 & 65 & - & - & - & 35 & - & - \\
\hline & L2 & 40 & - & - & - & 60 & - & - \\
\hline & $\mathrm{L} 3+\mathrm{L} 4$ & 74 & - & - & 3 & 23 & - & - \\
\hline \multirow{2}{*}{$\begin{array}{l}\text { AISI } 304 \\
\text { substrate }\end{array}$} & as received & - & - & - & - & 19 & 73 & 8 \\
\hline & annealed & - & - & - & - & 11 & 80 & 9 \\
\hline
\end{tabular}

Mechanical properties of the Ti-Cr-B-N and Ti-Al-Si-B-N coatings were inferred by nanoindentation. The mechanical properties, nano-hardness $\mathrm{H}$ and reduced Young's modulus $\mathrm{E}_{\mathrm{r}}$, are defined by the following formulas:

$$
H=\frac{P_{\max }}{A_{C}},
$$

where $\mathrm{P}_{\max }$ is the maximum load applied during the indentation, $\mathrm{A}_{\mathrm{C}}$ is the projection of the contact area of the at the maximum depth.

$$
\frac{1}{E_{r}}=\frac{1-v_{i}^{2}}{E_{i}}+\frac{1-v^{2}}{E},
$$

where $E_{i}$ and $E$ are the Young's modulus of the indenter tip (1171 GPa for diamond) and the sample, and $v_{\mathrm{i}}$ and $v$ are the Poisson coefficients of the indenter tip (0,04 for diamond) and of the sample, respectively. Load-displacement curves were recorded for in-plane and cross-section indentations. Fig. 12 shows such a comparison for a Ti-Cr-B-N sample, tested with $2000 \mu \mathrm{N}$ of maximum load. The as-deposited Ti-Cr-B-N and Ti-Al-Si-B-N coatings show no differences between load-displacement curves.

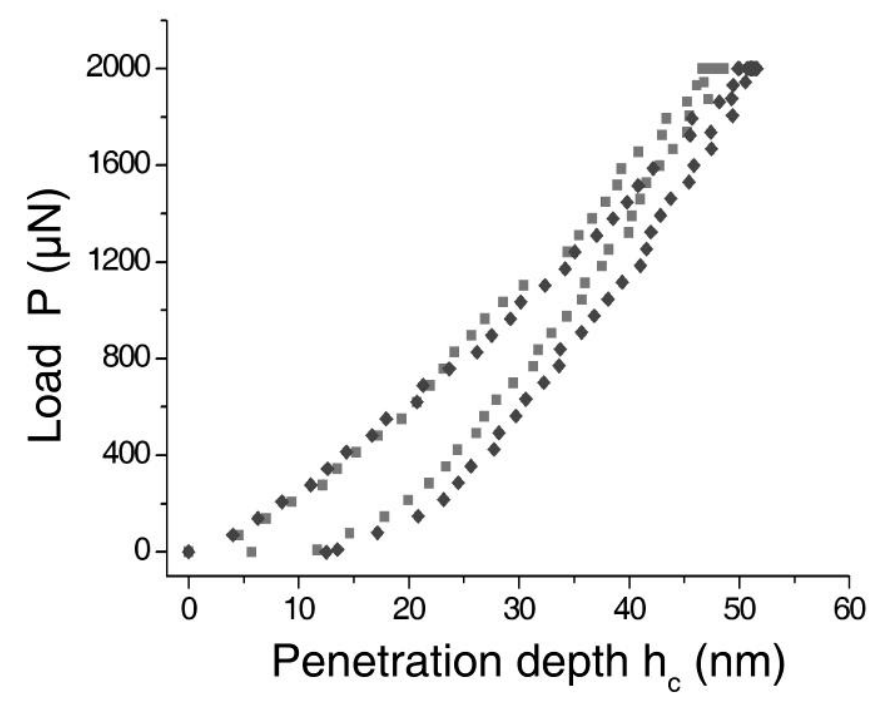

Fig. 12. Nano-indentation load-displacement curves measured for Ti-Cr-B-N coating with $2000 \mu \mathrm{N}$ of maximum load: $(\bullet)$ in plane indentation and $(\bullet)$ cross section indentation. 
Fig. 13(a) reports the values of the reduced Young's modulus, $\mathrm{E}_{\mathrm{r}} \approx 270 \mathrm{GPa}$, and hardness, $\mathrm{H} \approx 28$ $\mathrm{GPa}$, of the Ti-Cr-B-N/Si. Fig. 13(b) reports the values for Ti-Al-Si-B-N/Si: $\mathrm{E}_{\mathrm{r}} \approx 210 \mathrm{GPa}$, and $\mathrm{H} \approx$ $19 \mathrm{GPa}$. Furthermore, in Fig. 13, the hardness and Young's modulus of each single layer formed after the thermal treatment, measured on the cross-section, are reported for both coatings.

a)

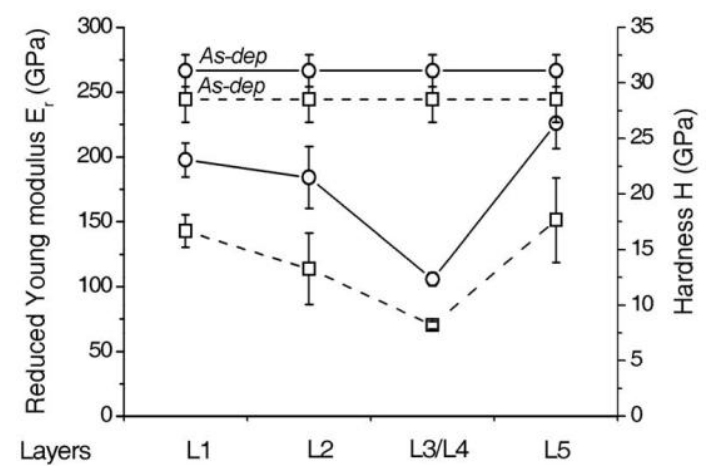

b)

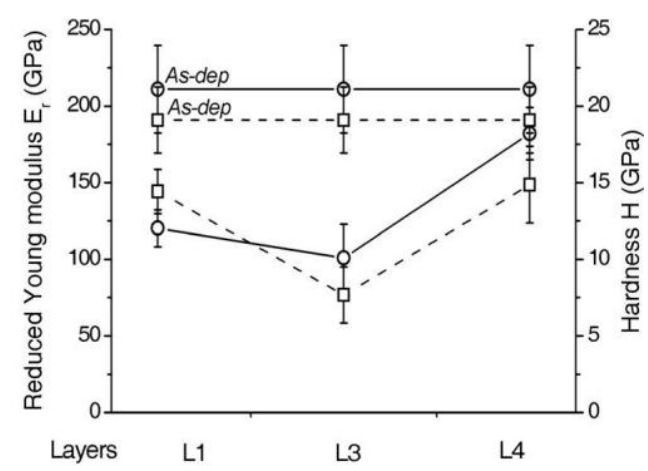

Fig. 13. Hardness (-----) and reduced Young's modulus (-○-) measured by nanoindentation on cross section of a) annealed Ti-Cr-B-N/Si, and b) annealed Ti-Al-Si-B-N/Si, for the different layers.

\section{Discussion}

\subsection{Cr-N coatings.}

In the present study, both $\mathrm{CrN}$ and $\mathrm{Cr}_{2} \mathrm{~N}$ phases have been reported in reactively sputtered $\mathrm{Cr}-\mathrm{N}$ films, depending on the Ar to $\mathrm{N}_{2}$ flow ratio during deposition. $\mathrm{CrN}$ (111) or (200) and $\mathrm{Cr}_{2} \mathrm{~N}$ (002) or (111) texture components were reported for the as-deposited $\mathrm{Cr}-\mathrm{N}$ films sputtered on $\mathrm{Si}(100)$ substrates, depending on the deposition parameters [56]. In particular the fraction of $\mathrm{Cr}_{2} \mathrm{~N}$ versus CrN was found to increase as $\mathrm{N}_{2} / \mathrm{Ar}$ flow ratio decreased, and the presence of both phases was detected at very low $\mathrm{N}_{2} / \mathrm{Ar}$ flow ratios [56]. Although there was no clear evidence of $\mathrm{Cr}_{2} \mathrm{~N}$ phase in the as-deposited samples, a contribution on the peak at $43.6^{\circ}$ from $\mathrm{Cr}_{2} \mathrm{~N}$ (111) plane is likely to exist. The relative reduction of $\mathrm{CrN}$ peaks and increase of contribution from $\mathrm{Cr}_{2} \mathrm{~N}$ (111) peak measured from sample A to sample $\mathrm{C}$ (Fig. 1) is consistent with the progressive reduction of $\mathrm{N}_{2}$ flow during sputtering. No presence of chromium oxide phase is visible on the as-deposited samples.

Phase transformation of $\mathrm{Cr}-\mathrm{N}$ films upon thermal anneal in air, vacuum and controlled atmosphere was investigated by other authors [56-58]. In some of these works phase transformation from $\mathrm{CrN}$ to $\mathrm{Cr}_{2} \mathrm{~N}$, upon thermal annealing in vacuum has been observed [57,58]. In some other works $\mathrm{Cr}_{2} \mathrm{~N}$ phase formation was observed under conditions for which it cannot be explained by thermodynamics considerations. It has been pointed out that phase transformation from $\mathrm{CrN}$ to $\mathrm{Cr}_{2} \mathrm{~N}$ phase can involve both thermodynamic and non-thermodynamic factors, such as stress relaxation induced phase transformation.

The more stable behavior of sample $\mathrm{C}$ with respect to vacuum thermal annealing can therefore be explained by the presence of a larger component of $\mathrm{Cr}_{2} \mathrm{~N}$ phase on the as-deposited sample (Fig. 2). This is consistent with the lower $\mathrm{N}_{2}$ flow used in sample $\mathrm{C}$, compared to sample $\mathrm{A}$ and B. The diffraction patterns reported in Fig. 3 also confirmed that, as expected, no chromium oxidation is occurred during vacuum annealing.

Chromium oxidation in $\mathrm{Cr}-\mathrm{N}$ films after thermal annealing in air was described by several other authors [58-60] and can be explained in terms of thermodynamics. The change in the Gibbs free energy associated with the oxidation reactions of respectively $\mathrm{CrN}$ and $\mathrm{Cr}_{2} \mathrm{~N}$ can be written as follows: 


$$
\begin{aligned}
& 2 \mathrm{CrN}_{(s)}+\frac{3}{2} \mathrm{O}_{2(g)}=\mathrm{Cr}_{2} \mathrm{O}_{3(s)}+N_{2(g)} \\
& \Delta G=\Delta G^{0}+R T \ln \left(p_{N_{2}} / p_{O_{2}}^{3 / 2}\right)= \\
& =(-883.368+0.101 \times T)+R T \ln \left(p_{N_{2}} / p_{O_{2}}^{3 / 2}\right) \quad(\mathrm{kJ} / \mathrm{mol}) \\
& C r_{2} N_{(s)}+\frac{3}{2} O_{2(g)}=C r_{2} O_{3(s)}+\frac{1}{2} N_{2(g)} \\
& \Delta G=\Delta G^{0}+R T \ln \left(p_{N_{2}}^{1 / 2} / p_{O_{2}}^{3 / 2}\right)= \\
& =(-1010.937+0.200 \times T)+R T \ln \left(p_{N_{2}}^{1 / 2} / p_{O_{2}}^{3 / 2}\right) \quad(\mathrm{kJ} / \mathrm{mol})
\end{aligned}
$$

where $\Delta G$ represents the change in the Gibbs free energy for this transformation; $\Delta G^{o}$ is the standard Gibbs free energy; $R$ is the gas constant; $T[\mathrm{~K}]$ is the absolute temperature, $p_{N_{2}}$ is the partial pressure of nitrogen and $p_{\mathrm{O}_{2}}$ is the partial pressure of oxygen. Using equation 3 and 4 to calculate Gibbs free energy change of both reactions for the present conditions $(\mathrm{T}=932.16 \mathrm{~K}$, air: $p_{\mathrm{N}_{2}}=0.79 \mathrm{~atm}$ and $p_{\mathrm{O}_{2}}=0.21 \mathrm{~atm}$ ) gives respectively $\Delta G$ equal to $-774 \mathrm{~kJ} / \mathrm{mol}$ and $-809 \mathrm{~kJ} / \mathrm{mol}$ for $\mathrm{CrN}$ and $\mathrm{Cr}_{2} \mathrm{~N}$ respectively. This implies that both phases tend to oxidize forming $\mathrm{Cr}_{2} \mathrm{O}_{3}$ layers and $\mathrm{Cr}_{2} \mathrm{~N}$ having higher tendency to oxidize. As discussed above, sample $\mathrm{C}$ is expected to have a higher $\mathrm{Cr}_{2} \mathrm{~N}$ content. This can explain the higher intensity of $\mathrm{Cr}_{2} \mathrm{O}_{3}$ peaks for a given annealing time on sample C compared to sample A (Fig. 1).

In reactively sputtered $\mathrm{Cr}-\mathrm{N}$ films, the formation of phases is strongly influenced by the deposition parameters: for instance, both $\mathrm{CrN}$ and $\mathrm{Cr}_{2} \mathrm{~N}$ phases have been reported in reactively sputtered $\mathrm{Cr}-\mathrm{N}$ films, depending on the Ar to $\mathrm{N}_{2}$ flow ratio during deposition [61]. No clear evidence of $\mathrm{Cr}_{2} \mathrm{~N}$ phase presence in the as-deposited films was found in the recorded diffraction patterns, such as the one of Fig. 4. The peaks at $38^{\circ}$ and $43.5^{\circ}$ in the GIXRD mode are rather broad and the proximity of the austenitic steel and $\mathrm{Cr}_{2} \mathrm{~N}$ peaks makes difficult their identification, while the weak peak at $63^{\circ}$ is only consistent with $\mathrm{CrN}$ (220) planes [62]. The presence of the $\mathrm{CrN}$ phase for the as-deposited samples was confirmed by the XRD measurement in $\theta-2 \theta$ configuration, where the $\mathrm{CrN}$ (220) peak at $63^{\circ}$ is clearly visible. Moreover, $\mathrm{Cr}-\mathrm{N}$ and substrate GIXRD peaks intensity decreases with temperature. From $T_{\max }=910 \mathrm{~K}$, peaks related to $\mathrm{Cr}_{2} \mathrm{O}_{3}$ phase appear on the diffraction pattern at angles of $24.5^{\circ}, 33.6^{\circ}$ and $36.2^{\circ}$, corresponding to $\mathrm{Cr}_{2} \mathrm{O}_{3}$ (012), (104) and (110) planes respectively $[52,62]$. Chromium oxidation in $\mathrm{Cr}-\mathrm{N}$ films after thermal annealing in air was reported by several other authors [59,61]. For $T_{\max }=1075 \mathrm{~K}$ a peak at $\theta=43^{\circ}$ developed. This peak indicates the presence of $\mathrm{Cr}_{2} \mathrm{~N}$ phase. Phase transformation from $\mathrm{CrN}$ to $\mathrm{Cr}_{2} \mathrm{~N}$ could be due to the stress relaxation occurring in the film during the oxidation at $T_{\max }=1075 \mathrm{~K}$ [63]. Furthermore, the diffraction patterns evolution with temperature reported in Fig. 4, shows the increase of the $\mathrm{Cr}_{2} \mathrm{O}_{3}$ (110) peak intensity relative to the $\mathrm{Cr}_{2} \mathrm{O}_{3}(012)$ and $\mathrm{Cr}_{2} \mathrm{O}_{3}(104)$ peaks.

Conversely, the increase of roughness and the detected presence of larger crystallites (diameter of $\sim 1 \mu \mathrm{m}$ ) in the $\mathrm{CrN}$ coatings is likely to be attributed to $\mathrm{Cr}_{2} \mathrm{O}_{3}$ crystallites. These result from oxidation of the film, as indicated by the GIXRD analyses. Roughness increases and appearance of large crystallites occurs after thermal cycling at $T_{\max }=910 \mathrm{~K}$ and become more evident at $T_{\max }=1075 \mathrm{~K}$, whereas thermal cycling at lower temperatures $(585 \mathrm{~K}$ and $755 \mathrm{~K})$ does not induce relevant morphological changes. As it can be seen, roughness is fairly stable up to $T_{\max }$ $=755 \mathrm{~K}$, starts increasing with temperature at $910 \mathrm{~K}$ and increases more rapidly at $T_{\max }=1075 \mathrm{~K}$. Moreover, as temperature increases, some portions of the $\mathrm{Cr}-\mathrm{N}$ coating start detaching from the surface. 
Hardness was found to reduce with penetration depth in the as-deposited and vacuum annealed conditions. This is attributed to the influence of the substrate on the measured hardness. A 'rule of thumb' requires that penetration depth is kept below one-tenth of the film thickness to contain the deformation within the film. On the other hand, relatively high penetration depths are required to achieve measurements not affected by the roughness of the system. Furthermore, for penetration depths near or lower than the indenter tip radius, the area function calibration is not reliable. For very thin films, these conditions are difficult to achieve, and measured hardness is often affected by the substrate [64,65]. AFM investigations showed that as-deposited and vacuum annealed samples have an RMS surface roughness of $\sim 15 \mathrm{~nm}$, which requires indentation depths above this value.

Hardness changes in $\mathrm{Cr}-\mathrm{N}$ coatings after vacuum annealing were also reported in other published works $[56,66]$. As for measurements on the as-deposited samples, the measured hardness depends on the penetration depth, and it can be concluded that the true hardness is $>20 \mathrm{GPa}$ for sample A, and $>15 \mathrm{GPa}$ for samples B and $\mathrm{C}$. Nano-hardness of sputtered $\mathrm{Cr}-\mathrm{N}$ films has been studied only for thicknesses greater than $\sim 500 \mathrm{~nm}$, whereas no data have been published in the thickness range considered in this study. The reported values of $\mathrm{Cr}-\mathrm{N}$ hardness are quite scattered [67] and in the range of 10 to $30 \mathrm{GPa}$. The change in hardness upon anneal can be attributed to two different factors: microstructure, i.e. phase transformations, and stress relaxation. The Cr-N films studied in this work, as in other, are expected to have a compressive stress, due to the different thermal expansion coefficients of $\mathrm{CrN}\left(2.3 \cdot 10^{-6} \mathrm{~K}^{-1}\right)$ [58] and AISI $304\left(\sim 17.8 \cdot 10^{-6} \mathrm{~K}^{-1}\right)$. Relaxation of compressive stress of Cr-N coatings is expected to occur in the temperature range of 670 to 870 $\mathrm{K}$ and should be accompanied by a reduction of hardness. In this work, the hardness rise indicates changes in the microstructure able to compensate the stress relaxation effects. The higher hardness rise was recorded in sample $A$, i.e. the sample where the observed $\mathrm{CrN}$ to $\mathrm{Cr}_{2} \mathrm{~N}$ phase transformation was larger. The hardness rises in samples $\mathrm{B}$ and $\mathrm{C}$ were lower compared to sample $\mathrm{A}$, and in this latter cases minimal microstructure modifications were detected by GIXRD.

\section{2. $\mathrm{Ti}-\mathrm{Cr}-\mathrm{B}-\mathrm{N}$ and $\mathrm{Ti}-\mathrm{Al}-\mathrm{Si}-\mathrm{B}-\mathrm{N}$ coatings.}

Columnar growth has often been reported for TiN. Depending on deposition process and parameters, nano-crystalline TiN and Ti-Si-N coatings can also follow this morphology [68,69]. In previous studies of Ti-Cr-B-N coatings deposited by IIAMS on $\mathrm{Si}$, similar texture and grain size to the present findings were reported, though no conclusive evidence of columnar growth was revealed [70,71]. In [71], TEM inspections of Ti-Cr-B-N films did not show a pronounced columnar structure, while AFM analyses showed a well-developed columnar structure.

Ti-Cr-B-N/Si coating showed a multilayered structure after air annealing. The top layer (L1) consists of large $\mathrm{TiO}_{2}$ grains, while a lower layer (L2) consists of a mixture of rutile-TiO ${ }_{2}$ and $\mathrm{Cr}_{2} \mathrm{O}_{3}$ grains. These results are consistent with earlier observations [36,72]. Under this region, a layer of about $1000 \mathrm{~nm}$ in thickness (L3) shows fine crystallites with similar morphology to L3 in the Ti-Al-Si-B-N coating. In L3 SAEDP diffraction pattern indicates the presence of TiN and possibly of $\mathrm{Cr}_{2} \mathrm{~N}$. Rather large voids can be seen in L2 and at the interface L1/L2 and L2/L3. Beneath it, a $150 \mathrm{~nm}$ thick layer (L4) seemed to be constituted by a mixture of amorphous phase and nanometric crystallites with smaller size respect to L3. The resultant SAEDPs (Fig. 10) show a clear ring-like diffraction, consistent with $\mathrm{Ti}_{2} \mathrm{~N}$ and $\mathrm{TiB}_{2}$ nano-crystallites. Finally, coarse grains with an average size of $500 \mathrm{~nm}$ constitute the layer directly in contact to the substrate (L5). EDS indicates a large content of $\mathrm{Cr}$ and some $\mathrm{Ti}, \mathrm{N}$ and $\mathrm{B}$ [73-75].

The microstructure features involved in the air annealed samples are rather complex, since mechanisms of diffusion (both self-diffusion of elements in the coating and diffusion of oxygen from the atmosphere), of residual stresses release and differential thermal expansion are involved. During oxidation, Ti- and Cr-oxide crystallites are formed on the coating surface. Since the $\mathrm{TiO}_{2}$ formation is thermodynamically favoured compared to $\mathrm{Cr}_{2} \mathrm{O}_{3}$ formation, coarse Ti-oxide grains grow rapidly on the coating surface. Outward Ti diffusion causes a depletion of Ti below L1 and promotes the formation of $\mathrm{Cr}_{2} \mathrm{O}_{3}$ in $\mathrm{L} 2$ [76]. Also in this case, the presence of $\mathrm{Ti}$ - and $\mathrm{Cr}$-oxide 
layers on the coating surface prevents the further inward oxygen diffusion; thus, the presence of $\mathrm{Ti}$ in $\mathrm{L} 3$ can be related to the formation of TiN phase, as XRD measurements have revealed. For the same reason, a $\mathrm{Cr}_{2} \mathrm{~N}$ phase, also detected by XRD, is present in $\mathrm{L} 3$.

Ti-Al-Si-B-N/Si showed a similar multilayered structure after air annealing. The first layer (L1) was characterized by the presence of $\mathrm{Al}$ and $\mathrm{O}$ (as detected by EDS). This suggested that $\mathrm{Al}_{2} \mathrm{O}_{3}$ crystallites formed as a consequence of the outward $\mathrm{Al}$ diffusion to the free surface $[75,76]$. Preferential oxidation of $\mathrm{Al}$ with respect to $\mathrm{Ti}$ at high temperature was reported by A. Joshi et al. in [81]. Next oxide layer (L2) is formed by $\mathrm{Ti}$ and $\mathrm{Al}$ oxide grains with diameter of $\sim 100 \mathrm{~nm}$. The formation of $\mathrm{Al}_{2} \mathrm{O}_{3} /$ mixed rutile- $\mathrm{TiO}_{2}+\mathrm{Al}_{2} \mathrm{O}_{3}$ structure in the high temperature range differs from the results reported in [37] for Ti-Al-N coatings. In [37] at $\mathrm{T} \geq 1070 \mathrm{~K}$, Joshi and Hu reported oxidation associated with the growth of well separated $\mathrm{Al}_{2} \mathrm{O}_{3}$ and $\mathrm{TiO}_{2}$ regions, with a layered structure becoming more evident with increasing oxidation time. Beneath L2 lies a layer (L3) with thickness of about $600 \mathrm{~nm}$, characterized by equiaxed crystals with a diameter ranging 10 to $45 \mathrm{~nm}$ and some elongated crystallites with length $<80 \mathrm{~nm}$ and a length-to-width ratio up to $4: 1$. This phase was identified by SAEDP as TiN. The last layer (L4), directly in contact to the substrate, was $200 \mathrm{~nm}$ thick and characterized by very small crystallites.

In the Ti-Al-Si-B-N film on steel, the oxidized coating fragments, constituted by two layers $(\mathrm{L} 1+\mathrm{L} 2)$, are not separated by a well-defined interface. An uncoated L2 layer has not been observed, thus, it was not possible to perform an EDS analysis on this layer. EDS data reports a higher content of $\mathrm{Al}$ in $\mathrm{L} 1+\mathrm{L} 2$ than in $\mathrm{L} 3$ and it suggests that the crystallites on the coating surface are likely to be constituted by $\mathrm{Al}_{2} \mathrm{O}_{3}$. These results are in agreement with Joshi and $\mathrm{Hu}$ [43], suggesting that a layered oxide structure $\mathrm{Al}_{2} \mathrm{O}_{3} / \mathrm{TiO}_{2}$ forms on the Ti-Al-nitride coating surface at temperatures above $1070 \mathrm{~K}$. Moreover, in L1 a high amount of $\mathrm{Cr}$ was detected. Since this element is not present in the as-deposited coating, it is believed that $\mathrm{Cr}$ atoms are made to diffuse from AISI 304 substrate toward the surface of the coating during thermal treatment, forming a Cr-rich oxide region. Cr presence in this layer is consistent with a reduction of concentration of $\sim 7 \%$ of atomic composition in the substrate after air annealing. Thus, $\mathrm{L} 1$ is constituted by a mixture of Al- and $\mathrm{Cr}-$ rich oxides and a certain amount of rutile- $\mathrm{TiO}_{2}$, as detected by XRD measurements. L3 shows a relative higher $\mathrm{Ti}$ and $\mathrm{Si}$ concentration and a consequent depletion of $\mathrm{Cr}$ and $\mathrm{Al}$ due to the outwards diffusion of these elements during oxidation. TiN phase could be present in L3, as XRD data revealed the presence of this phase after air annealing. It has been reported that $\mathrm{Al}_{2} \mathrm{O}_{3}$ can form a protective barrier which limit the inward oxygen diffusion in the Ti-nitride coating [76].

During the heating stage of the thermal treatment, release of the residual stresses occurs while the diffusion processes starts: oxygen diffuses inward into the coating, while other elements, such as $\mathrm{Ti}$, from the coating, and $\mathrm{Cr}$, from the coating/substrate interface, diffuse outward, thus forming oxidized sub-layers. As the oxides and the new phases formed at high temperature are created on the dilated substrate, they are subjected to a compression stress during the cooling phase of the thermal treatment. These mechanisms are responsible for a strong mechanical local stress on the oxidized coating, and the result is a spallation diffused all over the surface of the system [77]. The spallation mechanism revealed in the present study, was also described by Tolpygo and Clarke $[78,79]$ in relation to $\mathrm{Al}$ films deposited on a metallic substrate.

In Ti-Al-Si-B-N the independence of mechanical properties with respect to the indentation direction is consistent with the amorphous-like structure of the coating. XRD and TEM observation of Ti-Cr-B-N did show columnar growth formed by smaller crystals with preferential (200) orientation. Morphology and texture can influence mechanical properties of coatings [80]. If column sliding is the operating mechanism of plastic deformation, our result indicates that its effect on measured hardness and Young's modulus is the same for a stress parallel and perpendicular to the columns growth direction.

Nanoindentation measurement on annealed Ti-Al-Si-B-N/Si cross-section showed that the hardness of the layer L1 is consistent with values found in literature for films which a similar composition [81,82]: the hardness of $\mathrm{Al}_{2} \mathrm{O}_{3}$ changes with the microstructure, and can assume values up to $20 \mathrm{GPa}$ for a complete developed corundum structure. In this case, the values of $15 \mathrm{GPa}$ for 
the hardness and $120 \mathrm{GPa}$ for the reduced Young's modulus are typical for an $\alpha-\mathrm{Al}_{2} \mathrm{O}_{3}$ corundum phase. Hardness and reduced Young's modulus for the L2 zone of the coating could not be measured due to its small thickness. Hardness of layers L3 and L4 were $\sim 8$ and $\sim 15 \mathrm{GPa}$, respectively.

The hardness profile of the Ti-Cr-B-N/Si after annealing is much more complex. The hardness of L1 and L2 is respectively 17 and $12 \mathrm{GPa}$. The composition of L1, which is mainly a fully crystallized $\mathrm{TiO}_{2}$-rich layer, is consistent with the hardness value of rutile single crystal (18.5 $\mathrm{GPa}$ ), as reported in [83,84]. Depending on the amount of the crystallized phase, the hardness of $\mathrm{TiO}_{2}$ can vary from few $\mathrm{GPa}$, for a total amorphous and anatase-like structure, to $19 \mathrm{GPa}$, for a fully crystallized rutile crystal; in this case the hardness achieved is very close to the latter. The hardness of the zone L2 is due to the presence of two components, $\mathrm{TiO}_{2}$ and $\mathrm{Cr}_{2} \mathrm{O}_{3}$, whose hardness is respectively 18.5 and $18 \mathrm{GPa}[36,85,86]$ and to the microstructural presence of nanometre-size voids of Ti-Cr-B-N.

Due to their thicknesses, just an average value for the hardness of layers L3 and L4 was measured. The hardness of $\mathrm{L} 3 / \mathrm{L} 4,8 \mathrm{GPa}$, is similar to the value of the correspondent layer $\mathrm{L} 3$ for the Ti-Al-Si-B-N coated. L3/L4 of Ti-Cr-B-N and L3 of Ti-Al-Si-B-N also show similar morphology, but different phase composition, as seen by TEM observations. The hardest layer of Ti-Cr-B-N was L5, with an hardness value of $\sim 17.5 \mathrm{GPa}$. This bottom layer was characterized by large crystallites between the film and the substrate.

The mechanical characteristics of the tested samples are consistent to previously published results [87]. Mechanical response did not change significantly in both the coatings as $\mathrm{P}_{\max }$ increases, while after vacuum annealing, some modifications appear in the mechanical properties of both coatings. For the Ti-Al-Si-B-N coating, $\mathrm{E}_{\mathrm{r}}$ does not change, compared to the as deposited condition but the value of hardness decreases to $\sim 5 \mathrm{GPa}$. The vacuum annealed Ti-Cr-B-N showed a different behavior. $\mathrm{H}$ stayed at the same value $(\sim 30 \mathrm{GPa})$, while $\mathrm{E}_{\mathrm{r}}$ increased significantly, reaching the value of $~ 325 \mathrm{GPa}$.

One of the main factors affecting the Young's modulus is the nature of the atomic bonding, which is related to the atomic configuration of each component of the material. Interfaces and grain boundaries play an important role in the definition of the mechanical properties, since these zones are rich of lattice defects, voids, and lattice parameter mismatch [88]. Elastic modulus is also affected by material porosity [89], which is likely dependent on the preparation method of the film.

The effect of the atomic bonding, such as covalent, metallic and ionic, and the influence of the residual stresses have been studied by Karlsson et al. [90].

In Ti-Al-Si-B-N, compressive stress, due to the deposition, is responsible for the high values of hardness found in the as-deposited material. Different mechanisms are involved in decreasing of hardness for Ti-Al-Si-B-N ( 15 GPa) after vacuum annealing, such as the stress relaxation and the crystallization of the film in coarser grains or in new phases. The release of embedded Ar is another cause reduction of hardness. The presence of $\mathrm{Cr}$, diffused from the substrate, is responsible for the formation of crystalline $\mathrm{Cr}_{2} \mathrm{~N}$ phase, which contributes to the change of the $\mathrm{E}_{\mathrm{r}}$ value, also described by He et al. [88].

Conversely, in Ti-Cr-B-N, porosity level due to Ar incorporation, during deposition, seemed to be lower. On the other hand, Cr content was found to be higher in Ti-Cr-B-N than in Ti-Al-Si-B$\mathrm{N}$ : these two combined effects are believed to be responsible for the unchanged hardness upon annealing.

\section{Conclusions}

Crystal structure, surface morphology and hardness of thin $\mathrm{Cr}-\mathrm{N}$ coatings, deposited by reactive sputtering on AISI 304 stainless steel sheets, were investigated after deposition and after thermal annealing in air and vacuum.

- Transmission electron microscopy inspections showed that the as-deposited coatings have a very fine grain structure.

- CrN phase was found on all the samples, with a predominant (111) texture. 
- Annealing in vacuum induced formation of $\mathrm{Cr}_{2} \mathrm{~N}$ phase with (111) texture from $\mathrm{CrN}$ phase.

- Anneal in air induced formation of $\mathrm{Cr}_{2} \mathrm{O}_{3}$ phase, with higher oxidation speed for $\mathrm{Cr}_{2} \mathrm{~N}$ phase.

- Surface roughness increased for all the samples after annealing in air and large features appeared on the surface, as a consequence of $\mathrm{Cr}_{2} \mathrm{O}_{3}$ phase formation. $\mathrm{Cr}-\mathrm{N}$ coatings with higher $\mathrm{Cr}_{2} \mathrm{~N}$ phase content showed a modest roughness rise. Annealing in vacuum did not modify significantly surface roughness and morphology of the $\mathrm{Cr}-\mathrm{N}$ coatings for all the samples.

- Film hardness was above $10 \mathrm{GPa}$ for as-deposited $\mathrm{Cr}-\mathrm{N}$. Annealing in vacuum was found to increase hardness for all the samples, as a consequence of microstructure changes overcoming stress relaxation phenomena.

Thermal cycling tests were used to simulate the working conditions of nanometric $\mathrm{Cr}-\mathrm{N}$ coating deposited on AISI 304. Morphological and structural changes were characterized by XRD, GIXRD, SEM and AFM analyses. It was found that:

- Thermal cycling induces $\mathrm{CrN}$ oxidation to $\mathrm{Cr}_{2} \mathrm{O}_{3}$.

- Coating morphology changes gradually with temperature, due to $\mathrm{Cr}_{2} \mathrm{O}_{3}$ crystallites growth. For temperatures up to $T_{\max }=755 \mathrm{~K}$ crystallites size and roughness are quite stable. For temperature starting from $T_{\max }=910 \mathrm{~K}, \mathrm{Cr}_{2} \mathrm{O}_{3}$ crystallites size and the coating roughness starts increasing.

- Thermally induced stress generates cracks on the coatings, parallel to the substrate rolling direction, where $\mathrm{Cr}_{2} \mathrm{O}_{3}$ crystallites growth is favored. After cycling at $T_{\max }=1075 \mathrm{~K}$, the coating is highly oxidized, while large and numerous areas are detached from the substrate.

Ti-Al-Si-B-N and Ti-Cr-B-N deposited on AISI 304 stainless steel with a 2B superficial finishing have been investigated in the as-deposited condition and after air and vacuum annealing.

- The presence of layers with a different composition in the air annealed coatings is due to the affinity of $\mathrm{Ti}, \mathrm{Cr}$ and $\mathrm{Al}$ for oxygen at elevated temperature.

- The mechanical properties of the formed layers are different, and as a consequence, buckling of the coating in the cooling phase is reported.

- Cr diffuses from the substrate/coating interface to the surface of the film.

- The changes in the mechanical properties of the vacuum annealed films has been attributed to antagonist effects, such as the presence of Ar in the as-deposited coatings, the formation of new phases and modifications in the phases already present in the coating.

The microstructure and mechanical properties evolution of Ti-Cr-B-N and Ti-Al-Si-B-N coatings subjected to thermal oxidation were studied.

- As-deposited Ti-Cr-B-N showed columnar growth with TiN grains of 1-2 nm in diameter, whereas as deposited Ti-Al-Si-B-N was found to be amorphous. Identical values were found when measuring hardness and Young's modulus along directions parallel and perpendicular to column growth.

- After annealing, both coatings formed several oxidation layers, with several phases including fccTiN phase. Top layers are mainly constituted by $\mathrm{TiO}_{2}$ and $\mathrm{Cr}_{2} \mathrm{O}_{3}$ for Ti-Cr-B-N and by $\mathrm{TiO}_{2}$ and $\mathrm{Al}_{2} \mathrm{O}_{3}$ for Ti-Al-Si-B-N. In lower layers fcc-TiN phase is present. Mechanical properties of all layers are degraded compared with as-deposited coatings.

\section{Acknowledgements}

The authors gratefully acknowledge to Mr. D. Ciccarelli and Mr. M. Pieralisi for their help in the specimen preparations. This research has been financially supported by European FP6 framework program-EXCELL Project NoE 5157032 (website: www.noe-excell.net) and by V.I.N.F (Virtual Institute of NanoFilms, web site: www.vinf.eu).

\section{References}

[1] A.I.M. Bernstin: Handbook of Stainless Steels, (McGraw-Hill, New York 1977).

[2] T.M. Angeliu and P.L. Andresen: Corrosion Vol. 52 (1) (1996), p.28.

[3] H.G. Prengel, P.C. Jindal, K.H. Wendt, A.T. Santhanam, P.L. Hegde and R.M. Renich: Surf. Coat. Technol. Vol 139 (2001), p. 25. 
[4] H.P. Feng, S.C. Lee, C.H. Hsu and J.M. Ho: Materials Chemistry and Physics Vol. 59 (1999), p. 154.

[5] R.F. Bunshah: Handbook of Hard Coatings, (Noyes Publications, New York 2001).

[6] P. Engel, G. Schwarz and G.K. Wolf: Surf. Coat. Technol. Vol. 98 (1998), p. 1002.

[7] J.F. Lin, M.H. Liu and J.Du. Wu, Wear Vol. 194 (1996), p. 1.

[8] M. Pakala and R.Y. Lin: Surf. Coat. Technol. Vol. 81 (1996), p. 233.

[9] C. Meunier, S. Vives and G. Bertrand: Surf. Coat. Technol. Vol.107 (1998), p. 158.

[10] C. Rebholz, H. Ziegele, A. Leyland and A. Matthews: Surf. Coat. Technol. 115 (1999), p. 222.

[11] P. Hones, R. Sanjines and F. Levy: Surf. Coat. Technol. Vol. $94-95$ (1997), p. 398.

[12] J.P. Terrat, A. Gaucher and H. Hadj-Rabah: Surf. Coat. Technol. Vol. 45 (1991), p. 59.

[13] L. Cunha, M. Andritschky, L. Rebouta and K. Pischow: Surf. Coat. Technol. Vol. 116-119 (1999), p. 1152.

[14] K. Tfnshoff, A. Mohlfeld, T. Teyendecker, H.G. Fug, G. Erkens, R. Wenke, T. Cselle and M. Schwenk: Surf. Coat. Technol. Vol. 94-95 (1997), p. 603.

[15] S. Ortsmann, A. Savan, Y. Gerbig and H. Haefke: Wear Vol. 254 (2003), p. 1099.

[16] J.A. Sue and T.P. Chang: Surf. Coat. Technol. Vol. 76-77 (1995), p. 61.

[17] P. Karvankova, H. Männling and S. Veprek: Surf. Coat. Technol. Vol. 146-147 (2001), p. 280.

[18] S. Veprek and A.S. Argon: J. Vac. Sci. Technol. B Vol. 20 (2002), p. 650.

[19] A. Kawana, H. Ichimura, Y. Iwata and S. Ono: Surf. Coat. Technol. 86-87 (1996), p. 212.

[20] J. Creus, H. Idrissi, H. Mazille, F. Sanchette and P. Jacquot: Surf. Coat. Technol. Vol. 107 (1998), p. 183.

[21] I. Milosev and B. Navinsek: Surf. Coat. Technol. Vol. 60 (1993), p. 545.

[22] L. Cunha and M. Andritschky: Surf. Coat. Technol. Vol. 111 (1999), p. 162.

[23] R.A. Andrievski: J. Mater. Sci. Vol. 32 (1997), p. 4463.

[24] W. Gissler, M.A. Baker, J. Haupt, P.N. Gibson, R. Gilmore and T.P. Mollart: Diamond Film Technol. Vol. 7 (1997), p. 165.

[25] T.P. Mollart, J. Haupt, R. Gilmore and W. Gissler: Surf. Coat. Technol. Vol. 86-87 (1996), p. 231.

[26] R. Wiedemann, V. Weihnacht and H. Oettel: Surf. Coat. Technol. Vol. 116-119 (1999), p. 302.

[27] P.H. Mayrhofer and C. Mitterer: Surf. Coat. Technol. Vol. 133-134 (2000), p. 131.

[28] P. Holubar, M. Jilek and M. Sima: Surf. Coat. Technol. Vol. 120-121 (1999), p. 184.

[29] Q.Q. Yang, L.H. Zhao, H.Q. Du and L.S. Wen: Surf. Coat. Technol. Vol. 81 (1996), p. 287.

[30] P.H. Mayrhofer, M. Stoiber and C. Mitterer: Scr. Mater. Vol. 53 (2005), p. 241.

[31] A. Niederhofer, P. Nesládek, H.-D. Männling, K. Moto, S. Veprek and M. Jílek: Surf. Coat. Technol. Vol. 120-121 (1999), p. 173.

[32] H.-D. Männling, D.S. Patil, K. Moto, M. Jílek and S. Veprek: Surf. Coat. Technol. Vol. 146147 (2001), p. 263.

[33] W. Herr and E. Broszeit: Surf. Coat. Technol. Vol. 97 (1997), p. 335.

[34] D.Y. Wang, J.H. Lin and W.Y. Ho: Thin Solid Films Vol. 332 (1998), p. 246. 
[35] M. Wittmer, J. Noser and H. Melchior: J. Appl. Phys. Vol 52 (1981), p. 6659.

[36] Y. Otani and S. Hofmann: Thin Solid Films Vol. 287 (1996), p. 188.

[37] A. Joshi and H.S. Hu: Surf. Coat. Technol. Vol. 76-77 (1995), p. 499.

[38] F. Vaz, L. Rebouta, S. Ramos, M.F. da Silva and J.C. Soares: Surf. Coat. Technol. Vol 108109 (1998), p. 236.

[39] G. Llauro, F. Gourbilleau and R. Hillel: Thin Solid Films Vol. 315 (1998), p. 336.

[40] J.B. Choi, K. Cho, M.-H. Lee and K.-H. Kim: Thin Solid Films Vol. 447-448 (2004), p. 365.

[41] S. Veprek, M.G.J. Veprek-Heijman, P. Karvankova and J. Prochazka: Thin Solid Films Vol. 476 (2005), p. 1.

[42] S. Zhang, D. Sun and X. Zeng: J. Mater. Res. Vol. 20 (2005), p. 2754.

[43] P. Karvankova, M.G.J. Veprek-Heijman, M. Zawrah and S. Veprek: Thin Solid Films Vol. 467 (2004), p. 133.

[44] K.H. Lee, S.J. Jung, J.J. Lee and C.H. Park: J. Mater. Sci. Lett. Vol. 21 (2002), p. 423.

[45] S. Veprek, S. Reiprich and L. Shizhi: Appl. Phys. Lett. Vol. 66 (1995), p. 2640.

[46] D. McIntyre, J.E. Greene, G. Hakansson, J.E. Sundgren and W.D. Munz: J. Appl. Phys. Vol. 67 (1990), p. 1542.

[47] I.G. Brown: Rev. Sci. Instrum.Vol. 65 (1994), p. 3061.

[48] D.V. Shtansky, A.N. Sheveiko, M.I. Petrzhika, F.V. Kiryukhantsev-Korneeva, E.A. Levashov, A. Leyland, A.L. Yerokhin and A. Matthews: Surf. Coat. Technol. Vol. 200 (2005), p. 208.

[49] W.C. Oliver and G.M. Pharr: J. Mater. Res. Vol. 7 (1992), p. 1564.

[50] Z.B. Zhao, Z.U. Rek, S.M. Yalisove and J.C. Bilello: Thin Solid Films Vol. 472 (2005), p. 96.

[51] C. Paternoster, A. Fabrizi, R. Cecchini, M. El Mehtedi and P. Choquet: J. Mater. Sci. Vol. 43 (2008), p. 3377.

[52]. Powder Diffraction File, JCPDS International Center for Diffraction Data, Swarthmore, PA, (1992).

[53] F.-H. Lu and H.-Y. Chen: Thin Solid Films Vol. 398-399 (2001), p. 368.

[54] H.-Y. Chen and F.-H. Lu: Thin Solid Films Vol. 515 (2006), p. 2179.

[55] P. Scherrer: Gftt. Nachr Vol. 2 (1918), p. 98.

[56] A. Aubert, R. Gillet, A. Gaucher and J.P. Terrat: Thin Solid Films Vol. 108 (1983), p.165.

[57] P.H. Mayrhofer, G. Tischler and C. Mitterer: Surf. Coat. Technol. Vol. 142-144 (2001), p. 78.

[58] M. Odén, J. Almer, G. Håkansson and M. Olsson: Thin Solid Films Vol. 377-378 (2000), p. 407.

[59] P.H. Mayrhofer, H. Willmann and C. Mitterer: Surf. Coat. Technol. Vol. 146 (2001), p. 222.

[60] D.Y. Wang, J.H. Lin and W.Y. Ho: Thin Solid Films Vol. 332 (1998), p. 295.

[61] A. Barata, L. Cunha and C. Moura: Thin Solid Films Vol. 398 (2001), p. 501.

[62] C. Paternoster, A. Fabrizi, R. Cecchini and P.Choquet: High Temperature Materials and Processes Vol. 26 (2007), p. 349.

[63] K.-L. Chang, S.-C. Chung, S.-H. Lai and H.-C. Shih: Applied Surface Science Vol. 236 (2004), p. 406. 
[64] A. M. Korsunsky, M.R. McGurk, S.J. Bull and T.F. Page: Surf. Coat. Technol. Vol. 99 (1998), p. 171.

[65] H. Ichimura and I. Ando: Surf. Coat. Technol. Vol. 145 (2001), p. 88.

[66] J.N. Tu, J.G. Duh and S.Y. Tsai: Surf. Coat. Technol. Vol. 133-134 (2000), p. 181.

[67] W. Herr W and E. Broszeit : Surf. Coat. Technol. 97 (1997), p. 669.

[68] J.H. Huang, C.H. Lin, C.H. Ma and H. Chen: Script. Mater. Vol. 42 (2000), p. 573.

[69] F. Kauffmann, G. Dehm, V. Schier, A. Schattke, T. Beck, S. Lang and E. Arzt: Thin Solid Films Vol. 473 (2005), p. 114.

[70] D.V. Shtansky, Ph.V. Kiryukhantsev-Korneev, A.N. Sheveyko, A.E. Kutyrev and E.A. Levashov: Surf. Coat. Technol. Vol. 202 (2007), p. 861.

[71] D.V. Shtansky, S.A. Kulinich, E.A. Levashov, A.N. Sheveiko, F.V. Kiriuhancev and J.J. Moore: Thin Solid Films Vol. 420-421 (2002), p. 330.

[72] D.B. Lee: Surf. Coat. Technol. Vol. 173 (2003), p. 81.

[73] C. Paternoster, A. Fabrizi, R. Cecchini, S. Spigarelli, Ph.V. Kiryukhantsev-Korneev and A. Sheveyko: Surf. Coat. Technol. Vol. 203(2008), p. 736.

[74] A. Fabrizi, C. Paternoster, R. Cecchini, Ph.V. Kiryukhantsev-Korneev, A. Sheveyko, M. Cabibbo, M. Haidöpoulo and S. Spigarelli: Materials Science Forum Vol. 604-605 (2009), p. 19.

[75] P.V. Kiryukhantsev-Korneev, C. Paternoster, A. Fabrizi, A. N. Sheveyko, E.A. Levashov, E. Evangelista and D.V. Shtansky: Proceedings of EUROMAT-2007, Nurnberg (2007).

[76] S. Inoue, H. Uchida, Y. Yoshinaga and K. Koterazawa: Thin Solid Films Vol. 300 (1997), p. 171.

[77] V. K Tolpygo, J. R. Dryden, D. R. Clarke: Acta Mater. Vol. 46 (1998), p. 927.

[78] V.K. Tolpygo and D.R. Clarke: Mat. Sci. and Eng. Vol. A278 (2000), p. 142.

[79] V.K. Tolpygo and D.R.Clarke: Mat. Sci. and Eng. Vol. A278 (2000), p. 151.

[80] C.H. Ma, J.H. Huang, Haydn Chen: Surf. Coat. Technol. Vol. 200 (2006), p. 3868.

[81] O. Zywitzki and G. Hoetzsch: Surf. Coat. Technol. Vol. 94-95 (1997), p. 303.

[82] M. Birkholz, U. Albers and T. Jung: Surf. Coat. Technol. Vol. 179 (2004), p. 279.

[83] A. Bendavid, P.J. Martin, A. Jamting and H. Takikawa: Thin Solid Films Vol. 355-356 (1999), p. 6.

[84] A.O. Olofinjana, J.M. Bell and A.K. Jåmting: Wear Vol. 241 (2000), p. 174.

[85] D.B. Lee, M.H. Kim, Y.C. Lee and S.C. Kwon: Surf. Coat. Technol. Vol. 141 (2001), p. 232.

[86] F. Luo, K. Gao, X. Pang, H. Yang, L. Qiao, Y.Wang and A.A. Volinsky: Surf. Coat. Technol. 202 (2008), p. 3354.

[87] Ph.V. Kiryukhantsev-Korneev, D.V. Shtansky, M.I. Petrzhik, E.A. Levashov and B.N. Mavrin: Surf. and Coat. Technol. Vol. 201 (2007), p. 6143.

[88] G. He, J. Eckert, W. Loser and M. Hagiwara: Solid State Comm. Vol. 129 (2004), p. 711.

[89] M. Asmani, C. Kermel, A. Leriche and M. Ourak: J. Of Europ. Cer. Soc. Vol. 21 (2001), p. 1081.

[90] L. Karlsson, L. Hultman and J.-E.Sundgren: Thin Solid Films Vol. 371 (2000), p. 167. 